\title{
TRPM3 Channels Play Roles in Heat Hypersensitivity and Spontaneous Pain after Nerve Injury
}

\author{
Songxue Su, ${ }^{1,2}{ }^{\circledR}$ Yevgen Yudin, ${ }^{1}$ Nawoo Kim, ${ }^{1}{ }^{\circledR}$ Yuan-Xiang Tao, ${ }^{3}$ and ${ }^{\circledR}$ Tibor Rohacs ${ }^{1}$ \\ ${ }^{1}$ Department of Pharmacology, Physiology \& Neuroscience, New Jersey Medical School, Rutgers University, Newark, New Jersey 07101, \\ ${ }^{2}$ Department of Anatomy, College of Basic Medicine, Zhengzhou University, Zhengzhou 450001, Henan, China, and ${ }^{3}$ Department of Anesthesiology, \\ New Jersey Medical School, Rutgers University, Newark, New Jersey 07103
}

Transient receptor potential melastatin 3 (TRPM3) is a heat-activated ion channel in primary sensory neurons of the dorsal root ganglia (DRGs). Pharmacological and genetic studies implicated TRPM3 in various pain modalities, but TRPM3 inhibitors were not validated in TRPM3 $3^{-1-}$ mice. Here we tested two inhibitors of TRPM3 in male and female wild-type and $\mathrm{TRPM}^{-1-}$ mice in nerve injury-induced neuropathic pain. We found that intraperitoneal injection of either isosakuranetin or primidone reduced heat hypersensitivity induced by chronic constriction injury (CCI) of the sciatic nerve in wild-type, but not in TRPM3 ${ }^{-1-}$ mice. Primidone was also effective when injected locally in the hindpaw or intrathecally. Consistently, intrathecal injection of the TRPM3 agonist CIM0216 reduced paw withdrawal latency to radiant heat in wild-type, but not in TRPM $^{-1-}$ mice. Intraperitoneal injection of $2 \mathrm{mg} / \mathrm{kg}$, but not $0.5 \mathrm{mg} / \mathrm{kg}$ isosakuranetin, inhibited cold and mechanical hypersensitivity in CCI, both in wild-type and TRPM3 $3^{-1-}$ mice, indicating a dose-dependent off-target effect. Primidone had no effect on cold sensitivity, and only a marginal effect on mechanical hypersensitivity. Genetic deletion or inhibitors of TRPM3 reduced the increase in the levels of the early genes c-Fos and pERK in the spinal cord and DRGs in CCI mice, suggesting spontaneous activity of the channel. Intraperitoneal isosakuranetin also inhibited spontaneous pain related behavior in CCI in the conditioned place preference assay, and this effect was eliminated in TRPM $3^{-1-}$ mice. Overall, our data indicate a role of TRPM3 in heat hypersensitivity and in spontaneous pain after nerve injury.

Key words: heat; pain; TRPM3

Significance Statement

Neuropathic pain is a major unsolved medical problem. The heat-activated TRPM3 ion channel is a potential target for novel pain medications, but the pain modalities in which it plays a role are not clear. Here we used a combination of genetic and pharmacological tools to assess the role of this channel in spontaneous pain, heat, cold, and mechanical hypersensitivity in a nerve injury model of neuropathic pain in mice. Our findings indicate a role for TRPM3 in heat hyperalgesia, and spontaneous pain, but not in cold and mechanical hypersensitivity. We also find that not only TRPM3 located in the peripheral nerve termini, but also TRPM3 in the spinal cord or proximal segments of DRG neurons are important for heat hypersensitivity.

\section{Introduction}

Chronic pain is an unsolved medical problem; the lack of effective, but nonaddictive treatments against severe pain is a major driving force behind the search for novel analgesics. Transient receptor potential (TRP) channels are considered prominent

Received June 18, 2020; revised 0ct. 11, 2020; accepted Nov. 7, 2020.

Author contributions: S.S., N.K., Y.-X.T., and T.R. designed research; S.S., Y.Y., and N.K. performed research; S.S. and Y.Y. analyzed data; T.R. wrote the paper.

This study was supported by National Institutes of Health (NIH) | National Institute of Neurological Disorders and Stroke (NINDS) Grant NS-055159 and NIH | National Institute of General Medical Sciences Grants GM-131048 and GM-093290 to T.R.; and NIH | NINDS Grants NS-111553 and NS-113881 to Y.-X.T. TRPM3 ${ }^{-/-}$ mice were a gift from Dr. Thomas Voets (Katholieke Universiteit Leuven, Belgium).

The authors declare no competing financial interests.

Correspondence should be addressed to Tibor Rohacs at tibor.rohacs@rutgers.edu.

https://doi.org/10.1523/JNEUROSCl.1551-20.2020

Copyright $\odot 2021$ the authors drug targets, but so far no clinically useful medication targeting TRP channels has been developed. Most efforts focused on the heat- and capsaicin-sensitive TRP vanilloid 1 (TRPV1), but they largely failed mainly because of the severe, often life-threatening hyperthermia caused by TRPV1 antagonists (Carnevale and Rohacs, 2016). Here we evaluated the heat-sensitive TRP melastatin 3 (TRPM3) as an alternative drug target to treat evoked and spontaneous neuropathic pain.

TRPM3 is a $\mathrm{Ca}^{2+}$-permeable nonselective cation channel expressed in nociceptive neurons of the dorsal root ganglia (DRGs) and trigeminal ganglia (Oberwinkler and Philipp, 2014). It is activated by heat and chemical compounds, such as the endogenous neurosteroid pregnenolone sulfate (PregS; Wagner et al., 2008) and the synthetic compound CIM0216 (Held et al., 2015). Genetic deletion of TRPM3 in mice decreased sensitivity to noxious heat, as well as reduced inflammatory thermal 
hyperalgesia (Vriens et al., 2011). Furthermore, this channel is part of a trio of TRP channels, the combined deletion of which completely eliminated sensitivity to noxious heat in mice (Vandewauw et al., 2018). We and others recently reported that this channel is robustly inhibited by the activation of $\mathrm{G}_{\mathrm{i}}$-coupled receptors such as $\mu$-opioid receptors and $\mathrm{GABA}_{\mathrm{B}}$ receptors in DRG neurons (Badheka et al., 2017; Dembla et al., 2017; Quallo et al., 2017); thus, it may also be a downstream target of endogenous pain relief pathways.

While genetic deletion of TRPM3 leads to defects in noxious heat sensation (Vriens et al., 2011), the temperature threshold of the channel is such that it is activated well below noxious temperatures. For example, TRPM3 currents in HEK293 cells were shown to increase when the temperature was raised from $15^{\circ} \mathrm{C}$ to $26^{\circ} \mathrm{C}$, with a further increase at $37^{\circ} \mathrm{C}$ (Vriens et al., 2011). TRPM3 expressed in Xenopus oocytes showed an increase in currents when the temperature was raised from room temperature to $30^{\circ} \mathrm{C}$ (Zhao et al., 2020). This relatively low temperature threshold makes TRPM3 an ideal candidate for contributing to spontaneous pain in pathologic conditions, but this possibility has not yet been experimentally addressed.

Increased skin temperatures are sensed by the free nerve endings of the peripheral processes of DRG neurons (Vriens et al., 2014). TRP channels, however, have been shown to also be present in the central processes of DRG neurons that form synapses with the secondary neurons in the dorsal horn, and they can modulate the transmission of painful stimuli (Kim et al., 2014). TRPM3 RNA has also been detected in the spinal cord (Lee et al., 2003; Häring et al., 2018; Sathyamurthy et al., 2018). The role of TRPM3 in pain processing in the spinal cord and the proximal segments of DRG neurons (i.e., central processes, central termini, or cell bodies) has not yet been experimentally addressed.

Inhibitors of TRPM3 showed beneficial effects in some rodent pain models, and, unlike TRPV1 inhibitors, they do not increase body temperatures (Straub et al., 2013; Vriens and Voets, 2018). While the role of TRPM3 in noxious heat sensation and thermal hyperalgesia is well supported, its role in cold and mechanosensation is controversial, (Straub et al., 2013; Chen et al., 2014; Jia et al., 2017; Krügel et al., 2017). None of the results with TRPM3 inhibitors, however, were validated in TRPM3 ${ }^{-1-}$ animals; therefore, it is not clear which of the reported effects are mediated by TRPM3 inhibition (Behrendt, 2019).

Here we used TRPM3 $3^{-1-}$ mice and two different TRPM3 inhibitors to evaluate the role of this channel in various nociceptive conditions. We found that genetic deletion of TRPM3 reduced heat, but not mechanical threshold in basal conditions and in inflammation induced by paw injection of carrageenan. In the chronic constriction injury (CCI) model of neuropathic pain, intraperitoneal injection of isosakuranetin or primidone reduced heat sensitivity in wild-type (WT) mice, but not in $\mathrm{TRPM}^{-1-}$ mice. Mechanical and cold hypersensitivity after CCI were not affected by intraperitoneal injection of $0.5 \mathrm{mg} / \mathrm{kg}$ isosakuranetin or were only marginally affected by $1 \mathrm{mg} / \mathrm{kg}$ primidone. Isosakuranetin at $2 \mathrm{mg} / \mathrm{kg}$ reduced mechanical and cold hypersensitivity after CCI, but these effects were also observed in $\mathrm{TRPM}^{-1-}$ mice, suggesting an effect independent of TRPM3. Primidone was also effective in reducing heat, but not mechanical hypersensitivity in CCI when injected locally either in the hindpaw or intrathecally. Intrathecal injection of the TRPM3 agonist CIM0216 induced heat hypersensitivity in wild-type animals, but not in TRPM3 knock-out (KO) animals. Levels of the early genes c-Fos and pERK phosphorylated extracellular signalregulated kinase, indicators of neural activity, increased in both the DRGs and the spinal cords of CCI mice, and genetic deletion of TRPM3 reduced this increase, suggesting spontaneous activity of the channel in CCI, and its potential involvement in central sensitization. Intraperitoneal isosakuranetin also inhibited spontaneous pain-related behavior in CCI in the conditioned place preference (CPP) assay, and this effect was reduced, or eliminated in TRPM3 ${ }^{-1-}$ mice. Our data support the role of TRPM3 in heat hyperalgesia and spontaneous pain, but not in cold and mechanical hypersensitivity.

\section{Materials and Methods}

\section{Ethics statement}

All experiments were conducted in accordance with the ethical guidelines of the Rutgers New Jersey Medical School Animal Research Committee, and complied with the recommendations of the International Association for the Study of Pain. All procedures were approved by the Institutional Animal Care and Use Committee at the Rutgers New Jersey Medical School.

\section{Experimental animals}

Experiments were performed on male and female TRPM3-deficient mice (TRPM3-KO or TRPM3 ${ }^{-1-}$ ) and their WT counterparts (age, 79 weeks; weight, $22-25 \mathrm{~g}$ ). TRPM3 ${ }^{-1-}$ mice in the C57BL/6 background were a gift from Thomas Voets (Katholieke Universiteit, Leuven, Belgium; Vriens et al., 2011). The mice were bred using heterozygous breeding pairs, and we used wild-type littermates as controls for most experiments. Mice were kept in the Laboratory Animal Housing Faculty of Rutgers New Jersey Medical School at $24-25^{\circ} \mathrm{C}$, provided with standard mouse chow and water ad libitum and maintained under a $12 \mathrm{~h}$ light/dark cycle. Each mouse genotype was confirmed by PCR analysis. Experimenters were blind to treatment condition and, in most cases, to the mouse genotypes.

\section{$D R G$ neuron culture and $\mathrm{Ca}^{2+}$ imaging}

DRG neurons were prepared as described previously (Yudin and Rohacs, 2019). Briefly, mice were anesthetized with intraperitoneal injection of ketamine $(100 \mathrm{mg} / \mathrm{kg})$ and xylazine $(12 \mathrm{mg} / \mathrm{kg})$. The anesthetized animals were then perfused via the left ventricle with ice-cold HBSS (Thermo Fisher Scientific). Ganglia were collected after laminectomy and maintained in ice-cold HBSS during the isolation. After isolation, ganglia were incubated in an HBSS-based enzyme solution containing $2 \mathrm{mg} / \mathrm{ml}$ type I collagenase (Worthington) and $5 \mathrm{mg} / \mathrm{ml}$ dispase (SigmaAldrich) at $37^{\circ} \mathrm{C}$ for $25-30 \mathrm{~min}$, followed by repetitive trituration for dissociation. After centrifugation at $80 \mathrm{~g}$ for $10 \mathrm{~min}$, cells were resuspended and plated on round coverslips precoated with poly-L-lysine (Thermo Fisher Scientific) and laminin (Sigma-Aldrich). They were allowed to adhere for $1 \mathrm{~h}$; were maintained in culture in DMEM/F12 supplemented with $10 \%$ FBS (Thermo Fisher Scientific), $100 \mathrm{IU} / \mathrm{ml}$ penicillin, and $100 \mu \mathrm{g} / \mathrm{ml}$ streptomycin; and were kept in a humidity-controlled tissue culture incubator with $5 \% \mathrm{CO}_{2}$ at $37^{\circ} \mathrm{C}$ for $12-36 \mathrm{~h}$ before experiments.

$\mathrm{Ca}^{2+}$ imaging measurements were performed with an Olympus IX51 Inverted Microscope equipped with a DeltaRAM excitation light source (Photon Technology International), as described earlier (Yudin and Rohacs, 2019). Briefly, DRG neurons were loaded with $1 \mu \mathrm{M}$ fura-2 $\mathrm{AM}$ (Thermo Fisher Scientific) at $37^{\circ} \mathrm{C}$ for $40-50 \mathrm{~min}$ before the measurement, and dual-excitation images at 340 and $380 \mathrm{~nm}$ excitation wavelengths were detected at $510 \mathrm{~nm}$ with a Roper Cool-Snap digital CCD camera. Measurements were conducted in an extracellular solution containing the following (in mM): $137 \mathrm{NaCl}, 5 \mathrm{KCl}, 1 \mathrm{MgCl}_{2}, 2 \mathrm{CaCl}_{2}, 10$ HEPES, and 10 glucose, $\mathrm{pH}$ 7.4. Data analysis was performed using the Image Master software (PTI), and data were transferred to Microsoft Excel for further analysis and plotted in Origin 2019.

\section{Drugs and their administration}

Isosakuranetin was purchased from PhytoLab with a purity of $>98 \%$. The compound was freshly prepared with $5 \%$ Tween 80 in PBS. Different doses $(2,6$, and $10 \mathrm{mg} / \mathrm{kg}$ in a volume of $6 \mathrm{ml} / \mathrm{kg}$ body weight) were tested in naive mice by intraperitoneal injection to evaluate the 
most effective dosage. In the mice that underwent nerve injury, $2 \mathrm{mg} / \mathrm{kg}$ was used intraperitoneally. Behavior measurements were conducted 15 min after drug delivery, animals were killed for immunofluorescence measurements $30 \mathrm{~min}$ after drug delivery.

Primidone was purchased from Sigma-Aldrich. This compound was dissolved in sterile DMSO $(10 \mathrm{mg} / \mathrm{ml})$ and diluted in $0.5 \%$ Tween 80 in isotonic $\mathrm{NaCl}$ (Sigma-Aldrich), which was also used as vehicle control. Primidone was delivered with three distinct protocols: responses to 0.5 , 1 , and $2 \mathrm{mg} / \mathrm{kg}$ body weight were measured in naive mice by intraperitoneal injection, and $1 \mathrm{mg} / \mathrm{kg}$ was applied intraperitoneally in the mice with neuropathic pain. For intrathecal injection, $5 \mu \mathrm{l}$ of $460 \mu \mathrm{M}$ was administered $(2.3 \mathrm{nmol})$, and for intraplantar injection $10 \mu \mathrm{l}$ of $230 \mu \mathrm{M}$ was $(2.3 \mathrm{nmol})$ was injected. CIM0216, the potent agonist of TRPM3, was purchased from Calbiochem (EMD Millipore) with a purity of $98.3 \%$, and was dissolved in DMSO. The working solutions were diluted from the stock solution $(100 \mathrm{mM}$ ) with vehicle (combination of $88 \% \mathrm{NaCl}, 10 \%$ PEG-200, and 2\% Tween 80 ). For intrathecal injection ( $25 \mathrm{nmol})$, a volume of $5 \mu \mathrm{l}$ with a concentration of $5 \mathrm{~mm}$ was delivered slowly. All measurements were conducted 30-60 min after drug delivery.

Intrathecal administration. Intrathecal injection was performed as previously described (Gao et al., 2010; Berta et al., 2014; Lee et al., 2018). Briefly, a $25 \mu \mathrm{l}$ microsyringe (30 ga needle coupled to a Hamilton syringe) was inserted between the L5 and L6 segments under light isoflurane anesthesia (3\%), and the flick or formation of an "S" shape by the tail was considered as a successful injection. Drugs were injected into the subarachnoid space with a total volume of $5 \mu \mathrm{l}$ at a constant rate of $10 \mu \mathrm{l} /$ min. Measurements were performed $30 \mathrm{~min}$ after intrathecal drug delivery.

\section{Pain models}

Carrageenan-induced inflammatory pain model. Paw inflammation was evoked by unilateral subcutaneous injection with $20 \mu \mathrm{l}$ of a $1 \%$ solution of $\lambda$-carrageenan [dissolved in $0.9 \%$ sodium chloride (SigmaAldrich) into the dorsal surface of the left hindpaw; Woodhams et al., 2019]. Behavioral measurements were performed throughout a $2 \mathrm{~d}$ experimental period, as indicated in the figure legend. Immunofluorescence staining was performed at $4 \mathrm{~h}$ after carrageenan administration.

Sciatic nerve chronic constriction injury-induced neuropathic pain model. For CCI-induced neuropathic pain, the surgery was performed as described previously (Tanimoto-Mori et al., 2008; Li et al., 2015b, 2017). Briefly, after the animals were anesthetized with ketamine and xylazine, and randomly divided into the sham-operated and unilateral CCI model groups. The left sciatic nerve trunk was exposed by blunt dissection at mid-thigh level, and three ligatures were tied loosely with 7-0 silk thread around the nerve with $1 \mathrm{~mm}$ spacing. The sham groups underwent procedures identical to that in the CCI group, but without the ligature of the respective nerve. Behaviors were examined before the surgery and $6 \mathrm{~d}$ after surgery with drug treatments. Immunofluorescence measurements were conducted $6 \mathrm{~d}$ after the surgery; animals underwent CCI surgery on one side, sham operation on the other side.

\section{Behavior tests}

Animals were acclimatized to the testing room for at least $1 \mathrm{~h}$ before all behavioral tests. The same experimenter handled and tested all animals in each experiment, and was blinded to the treatment and, in most cases, to the genotype of the animals. Both male and female mice were used, and the data were pooled together as we did not observe a significant difference between the sexes.

\section{Evoked pain behavior analysis}

Mechanical, heat, and cold tests were conducted as described previously (Bennett and Xie, 1988; Nadal et al., 2006; Tanimoto-Mori et al., 2008; Li et al., 2017). There was a $1 \mathrm{~h}$ interval between the two tests.

von Frey filament test. Mechanical sensitivity was assessed by paw withdrawal responses to von Frey filament stimuli (Li et al., 2017, 2020). Mice were acclimatized on a metal mesh floor in an individual Plexiglas chamber for $1 \mathrm{~h}$. The mechanical sensitivity was evaluated using two calibrated von Frey filaments ( 0.07 and $0.4 \mathrm{~g}$ ). They were used to stimulate the hindpaw for $\sim 1 \mathrm{~s}$, and each stimulation was repeated 10 times to both hindpaws with a $5 \mathrm{~min}$ interval. Paw withdrawal responses in each of these 10 applications were represented as a percentage response frequency $[$ (number of paw withdrawals $/ 10$ trials $) \times 100=\%$ response frequency].

Hargreaves test. Thermal sensitivity of the paw was assessed with a Model 336 Analgesia Meter (IITC Life Science). Mice were acclimatized on a glass floor in small Plexiglas chambers for $1 \mathrm{~h}$, after which a light beam was focused on the midplantar region of the of the hindpaw. The latency to respond by withdrawing the paw from the light was recorded. The intensity of the light beam was adjusted to achieve an average baseline paw withdrawal latency of $\sim 10-12 \mathrm{~s}$ in naive mice. The cutoff time was $20 \mathrm{~s}$ to prevent tissue damage. Stimuli were applied to the paws three to five times at $5 \mathrm{~min}$ intervals, and the average latency was calculated (Nadal et al., 2006; Li et al., 2017).

Cold plate test. Paw withdrawal responses to noxious cold $\left(0^{\circ} \mathrm{C}\right)$ and innocuous cold $\left(5^{\circ} \mathrm{C}\right)$ were examined when the animal was placed in an individual Plexiglas chamber on a cold aluminum plate, the temperature of which was monitored continuously by a thermometer. For the response to noxious cold $\left(0^{\circ} \mathrm{C}\right)$, the duration between hindpaw placed on the plate and paw flinching was recorded as paw withdrawal latency. Each test was repeated three times at $10 \mathrm{~min}$ intervals for the paw on the ipsilateral side. To avoid tissue damage, a cutoff time of $20 \mathrm{~s}$ was used (Cao et al., 2015b; Li et al., 2017). For the response to innocuous cold (5 ${ }^{\circ}$ $\mathrm{C})$, each mouse was placed on the cold plate, which was preset at a temperature of $5^{\circ} \mathrm{C}$. The number of times the mouse lifted up or flinched its paw was recorded for the duration of $5 \mathrm{~min}$. The scores were obtained by subtracting the contralateral paw lifts count from the ipsilateral paw lifts count (Nadal et al., 2006; Tanimoto-Mori et al., 2008).

\section{Spontaneous pain test}

Conditioned place preference. CPP was performed $6 \mathrm{~d}$ after CCI or sham operations as described previously (Mo et al., 2018; Sun et al., 2019). Animals were first preconditioned with full access to two different Plexiglas chambers connected through an internal door (Med Associates) for $30 \mathrm{~min}$; after that, the time spent in each chamber was recorded as the baseline within $15 \mathrm{~min}$. The conditioning protocol was performed for the following $3 \mathrm{~d}$ with the internal door closed. Each mouse received intraperitoneal injection of vehicle specifically paired with one conditioning chamber for $30 \mathrm{~min}$ in the morning. Six hours later, isosakuranetin (2 or $0.5 \mathrm{mg} / \mathrm{kg}$ body weight) was given intraperitoneally paired with another conditioning chamber for $30 \mathrm{~min}$ in the afternoon. On the test day, the mice were placed in one chamber with free access to both chambers. The duration of time that each mouse spent in each chamber was recorded for $15 \mathrm{~min}$. CPP scores were calculated by subtracting preconditioning time from test time spent in the isosakuranetin-paired chamber.

\section{Immunofluorescence}

Animals were deeply anesthetized with ketamine and xylazine and transcardially perfused with $20 \mathrm{ml}$ of $0.01 \mathrm{M}$ PBS, $\mathrm{pH} 7.4$, followed by $20 \mathrm{ml}$ of $4 \%$ paraformaldehyde (PFA) in $0.1 \mathrm{~m}$ phosphate buffer, $\mathrm{pH}$ 7.4. The tissues of L3-L5 DRGs and the corresponding spinal cord from each group were collected, and postfixed in $4 \%$ paraformaldehyde at $4^{\circ} \mathrm{C}$ for $4 \mathrm{~h}$, followed by dehydration in gradient from $20-30 \%$ sucrose in $0.01 \mathrm{~m}$ PBS solution at $4^{\circ} \mathrm{C}$ overnight. The DRGs were sectioned into $12-\mu \mathrm{m}$-thick slices, and the spinal cords were sectioned into $14-\mu \mathrm{m}$-thick slices. After the sections were blocked for $1 \mathrm{~h}$ at room temperature in blocking solution (UltraCruz Blocking Reagent, catalog \#sc-516214, Santa Cruz Biotechnology), they were incubated with the following primary antibodies overnight at $4^{\circ} \mathrm{C}$ : mouse anti-c-Fos (E-8; 1:80; catalog \#sc166940, Santa Cruz Biotechnology) and rabbit anti-pERK (1:200; catalog \#p160-2024, PhosphoSolutions). The sections were then incubated with either goat anti-mouse antibody conjugated to Cy3 (1:600; Jackson ImmunoResearch) and goat anti-rabbit conjugated to $\mathrm{Cy} 3$ (1:600; Jackson ImmunoResearch) for $2 \mathrm{~h}$ at room temperature. Control experiments included the substitution of normal mouse or rabbit serum for the primary antiserum and omission of the primary antiserum. The sections were finally mounted using DAPI mounting medium (SigmaAldrich). Immunofluorescence-labeled images were examined using a Leica DMI4000 Fluorescence Microscope and captured with a 
DFC365FX camera (Leica) or a Nikon Ti2-E Microscope equipped with an ORCA-Fusion Gen-III Camera. Labeled cells were quantified using the NIH ImageJ software. Consistent with earlier publications, c-Fos staining showed predominantly cytoplasmic location in DRG neurons (Koh et al., 2014; Liu et al., 2015).

In situ hybridization RNAscope assay

After perfusion under deep anesthesia, L3-L5 DRGs and the corresponding spinal cords were collected from mice; the tissues were postfixed and dehydrated with the same protocol as applied in immunofluorescence measurements. DRGs and spinal cords were sectioned into 12- and 14- $\mu \mathrm{m}$-thick slices, respectively.

RNAscope assay was then conducted as described previously (Adriaenssens et al., 2019; Warren et al., 2019). Simultaneous detection of mouse TRPM3, GFAP, and NeuN was performed on fixed DRGs and spinal cord sections using Advanced Cell Diagnostics (ACD) RNAscope 2.5 LS Multiplex Reagent Kit, Probe-Mm-Trpm3, and Probe-MmGFAP-C2, and Probe-Mm-Rbfox3-C3 (NeuN; ACD). Positive (RNAscope 3-plex LS Multiplex Control Positive Probe-Mm polr2A, ppib, ubc; ACD) and negative (RNAscope 3-plex LS Multiplex Negative Control Probe dapB; ACD) controls were performed in parallel. The sections were then postfixed in prechilled $4 \%$ PFA for $15 \mathrm{~min}$ at $4^{\circ} \mathrm{C}$ and washed three times with PBS for $5 \mathrm{~min}$ each before dehydration through 50,70 , and $100 \%$ and $100 \%$ ethanol for 5 min each. Slides were air dried at room temperature, and a hydrophobic barrier was drawn around the section. We then treated slides with a protease (Pretreatment 4) for $20 \mathrm{~min}$ and washed them in distilled water. Probe hybridization and signal amplification were performed according to manufacturer instructions. The following TSA Plus fluorophores were used to detect corresponding RNAscope probes according to the ACD protocol: Opal 520, 570, and 690 Reagent Kits (Akoya Biosciences). Slides were then mounted using DAPI (ACD). Slides were imaged on a Nikon A1R confocal microscope with a $40 \times$ oil-objective; the images were quantified using CellProfiler software (Erben et al., 2018).

\section{Experimental design and statistical analysis}

All the sample sizes and experimental designs were based on data previously published in our laboratory and similar experiments in this field. Data are presented as the mean \pm SD or mean \pm SEM and scatter plots, with the number of experimental replicates indicated in each figure legend. Statistical analysis was performed using GraphPad Prism 8.0 or Microcal Origin 2019 software. The normality of data distribution was tested with the Kolmogorov-Smirnov test. One-way, two-way, or three-way ANOVA followed by Tukey's post hoc test was used to assess significance, as indicated in each figure legend. The $p$ values shown in the figures are from pairwise comparisons from Tukey's test; $p$ and $F$ values for overall ANOVA for individual factors and their interactions are described in the figure legends. $p$ Values of $<0.05$ were considered significantly different.

\section{Results}

The goal of this study is to assess the role of the TRPM3 ion channel in various nociceptive conditions, using two TRPM3 inhibitors and $\mathrm{TRPM}^{-1-}$ mice. First, we validated the TRPM $3^{-1-}$ mice by performing $\mathrm{Ca}^{2+}$ imaging experiments on DRG neurons isolated from wild-type and TRPM $3^{-I-}$ mice. Consistent with earlier reports (Vriens et al., 2011), we found that wild-type, but not TRPM3 ${ }^{-/-}$, DRG neurons displayed robust $\mathrm{Ca}^{2+}$ increases in response to the application of the TRPM3 agonist pregnenolone sulfate $(12.5 \mu \mathrm{M}$; Fig. $1 A, B)$. Unlike wild-type neurons, TRPM3 ${ }^{-1-}$ DRG neurons also lacked responses to CIM0216 $(1 \mu \mathrm{M})$, the synthetic agonist of TRPM3, but they responded to capsaicin $(0.2 \mu \mathrm{M})$, the agonist of TRPV1, and menthol $(500 \mu \mathrm{M})$, the agonist of TRPM8 channels (data not shown). These data validate the lack of functional TRPM3 channels in $\mathrm{TRPM}^{-1-}$ mice.

\section{TRPM3 plays a role in thermal hyperalgesia but not in mechanical allodynia in inflammation}

$\mathrm{TRPM}^{-1-}$ mice were shown to display reduced basal heat sensitivity and thermal hyperalgesia, but no impairment in mechanical sensitivity after inflammation induced by local injection of Complete Freund's Adjuvant (CFA; Vriens et al., 2011). Here we tested heat and mechanical sensitivity before and after hindpaw injection of carrageenan. Figure 1, $C$ and $D$, shows that TRPM3 ${ }^{-1-}$ mice showed reduced basal sensitivity to radiant heat compared with wild-type mice. Injection of carrageenan induced a robust decrease in paw withdrawal latency to radiant heat in wild-type mice, but not in TRPM3 ${ }^{-1-}$ mice. Responses to mechanical stimuli using von Frey filaments, on the other hand, were not different between wild-type and TRPM3 $3^{-1-}$ mice (Fig. $1 E-H$ ) in baseline conditions, and after carrageenan injection. These data are consistent with earlier findings showing that TRPM3 plays a role in responses to heat, but not to mechanical stimuli (Vriens et al., 2011).

Next, we compared the levels of c-Fos and pERK, two pronociceptive signal transduction proteins in L3-L5 DRGs and the corresponding dorsal horn in TRPM3 ${ }^{-1-}$ mice and wild-type littermates with or without carrageenan injection. Figure 2 shows that the number of c-Fos- and pERK-positive cells increased both in the DRGs (Fig. 2A,C) and the dorsal horn (Fig. 2B,D) after carrageenan injection. This increase was significantly smaller in DRGs from TRPM3 ${ }^{-1-}$ mice compared with wild-type littermates both for c-Fos and pERK (Fig. 2C). Similarly, in the dorsal horn, the increase induced by carrageenan in c-Fos and pERK (Fig. 2D) was smaller in TRPM $3^{-1-}$ mice than in wild-type littermates. These data indicate the importance of TRPM3 in transmitting painful stimuli in carrageenan-induced inflammation.

\section{TRPM3 is important for thermal hyperalgesia, but plays no major role in cold or mechanical hypersensitivity in neuropathic pain}

It was reported that systemic injection of the TRPM3 antagonist isosakuranetin (1.5-6 mg/kg; Jia et al., 2017) and liquiritigenin (Chen et al., 2014) reduced not only heat, but mechanical and cold sensitivity in the CCI model of peripheral neuropathy in rats.

Here we revisited the role of TRPM3 in heat, cold, and mechanical sensitivity in neuropathic pain using inhibitors and $\mathrm{TRPM}^{-1-}$ mice. First, we tested the dose dependence of isosakuranetin on sensitivity to radiant heat in naive mice. Figure $3 \mathrm{~A}$ shows that intraperitoneal injection of $2 \mathrm{mg} / \mathrm{kg}$ isosakuranetin induced a significant increase in paw withdrawal latency to radiant heat. Higher doses $(6$ and $10 \mathrm{mg} / \mathrm{kg}$ ) showed smaller effects, consistent with an earlier report (Straub et al., 2013); therefore, we proceeded with $2 \mathrm{mg} / \mathrm{kg}$ for subsequent experiments.

Next, we performed CCI operation on the mice and tested sensitivity to radiant heat. Figure $3 B$ shows that wild-type CCI animals displayed a significant reduction in paw withdrawal latency compared with sham-operated animals. TRPM $3^{-1-} \mathrm{CCI}$ mice on the other hand displayed no reduction in withdrawal latency to radiant heat, showing the importance of TRPM3 in neuropathic heat hyperalgesia. Intraperitoneal injection of $2 \mathrm{mg} / \mathrm{kg}$ isosakuranetin increased the latency of paw withdrawal from radiant heat in wild-type sham-operated mice to levels similar to those observed in TRPM3 $3^{-1-}$ mice (Fig. $3 B$ ). Isosakuranetin also significantly increased the paw withdrawal latency in wild-type CCI mice, but the withdrawal latency was still lower than that observed in TRPM3 ${ }^{-1-}$ mice (Fig. 3B). In TRPM3 ${ }^{-1-}$ mice isosakuranetin had no effect on paw withdrawal latency in either 
A



C

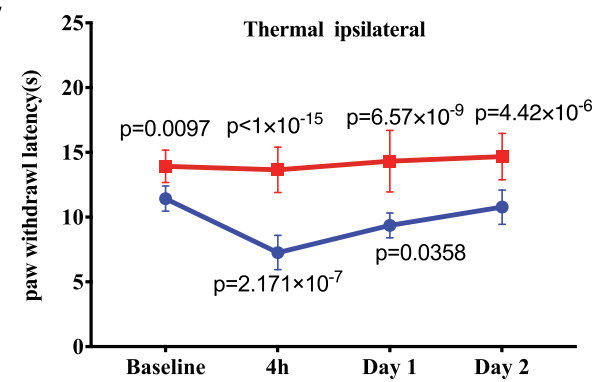

E

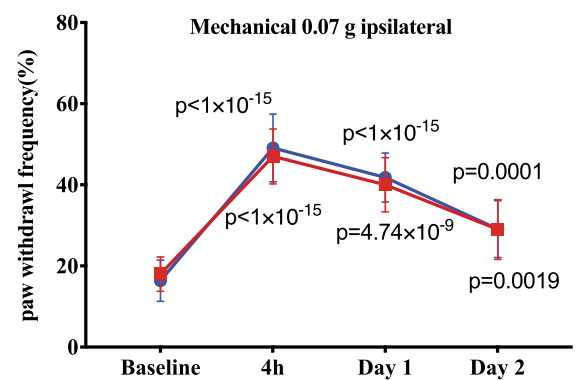

G

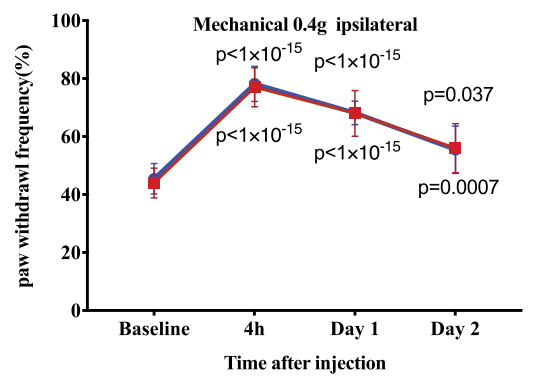

B



D

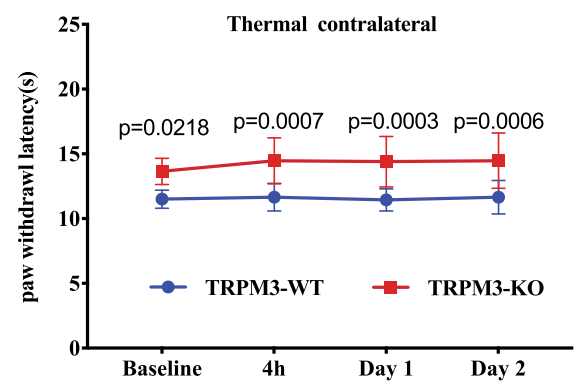

$\mathbf{F}$

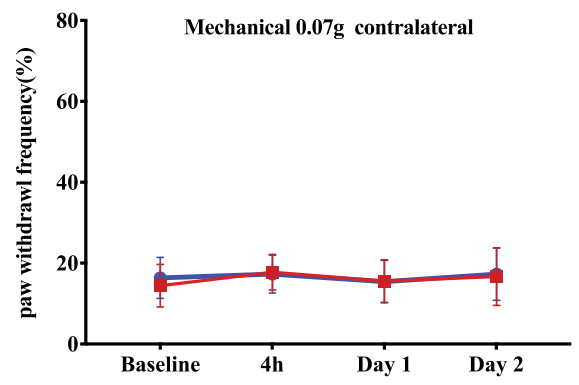

H

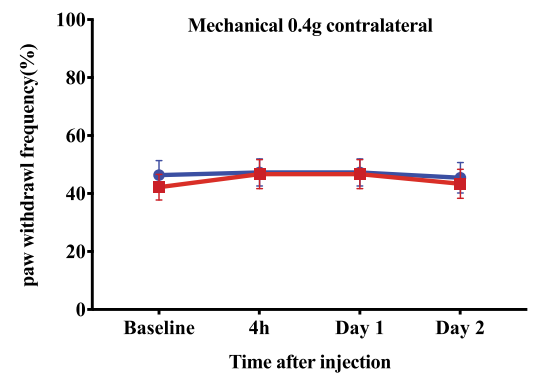

Figure 1. TRPM3 deficiency reduces hypersensitivity to thermal, but not to mechanical, stimuli in carrageen-induced inflammatory pain. $\boldsymbol{A}, \boldsymbol{B}, \mathrm{Ca}^{2+}$ imaging experiments on isolated DRG neurons from wild-type $(\boldsymbol{A})$ and TRPM3 ${ }^{-1-}(\boldsymbol{B})$ mice. The applications of $12.5 \mu \mathrm{m}$ PregS and $30 \mathrm{~mm} \mathrm{KCl}$ are indicated by the horizontal lines. Data are shown as the mean \pm SEM $n=69$ for all PregS responsive neurons from one DRG isolation for wild-type mice, and $n=197$ neurons for TRPM3 ${ }^{-1-}$ mice from a separate DRG neuron isolation on the same day. Three independent DRG neuron isolations both from wild-type mice and from TRPM-I- mice were performed, and PregS was applied in all three of them with similar results. $\boldsymbol{C}, \boldsymbol{D}$, Latencies to thermal stimuli after hind paw injection of carrageenan in the Hargreaves test of ipsilateral $(\boldsymbol{C})$ and contralateral $(\boldsymbol{D})$ sides of TRPM3-KO mice and wild-type littermates (TRPM3-WT; $n=9-11$ ). The $p$ values on the top indicate a difference between TRPM3-KO and TRPM3-WT mice; $p$ values at the bottom indicate a difference from the baseline of TRPM3-WT mice. Data are expressed as the mean \pm SD. Statistical significance was calculated with two-way ANOVA (genotype $\times$ time) and Tukey's post hoc test $\left(F_{\text {genotype }(1,72)}=173.43, p<1 \times 10^{-15} ; F_{\text {time }(3,72)}=9.91, p=1.5 \times 10^{-5} ; F_{\text {genotype } \times \text { time(3,72) }}=6.00, p=0.001\right)$ for the ipsilateral side. $\boldsymbol{E}-\boldsymbol{H}$, Paw withdrawal frequencies to mechanical stimulation at $0.07 \mathrm{~g}(\boldsymbol{E}$, ipsilateral; $\boldsymbol{F}$, contralateral) and $0.4 \mathrm{~g}(\boldsymbol{G}$, ipsilateral; $\boldsymbol{H}$, contralateral) in von Frey filament test of TRPM3-WT and TRPM3-K0 mice ( $n=9$ 11), $p$ values on top show a difference from baseline in TRPM3-KO mice; $p$ values in the bottom show difference from baseline for TRPM3- WT mice. Bars represent the mean \pm SD. Statistical significance was calculated with two-way ANOVA (genotype $\times$ time) and Tukey's post hoc test $\left(F_{\text {genotype }(1,76)}=0.17, p=0.68 ; F_{\text {time }}(3,76)=89.9, p<1 \times 10^{-15}\right.$; $F_{\text {genotype }} \times$ time(3,76) $=0.36, p=0.78$ for the values of ipsilateral side at $0.07 \mathrm{~g} . F_{\text {genotype }(1,76)}=0.15, p=0.70 ; F_{\text {time }(3,76)}=98.6, p<1 \times 10^{-15} ; F_{\text {genotype }} \times$ time(3,76) $=0.10$, $p=0.96$ for the values of ipsilateral side at $0.4 \mathrm{~g}$. 


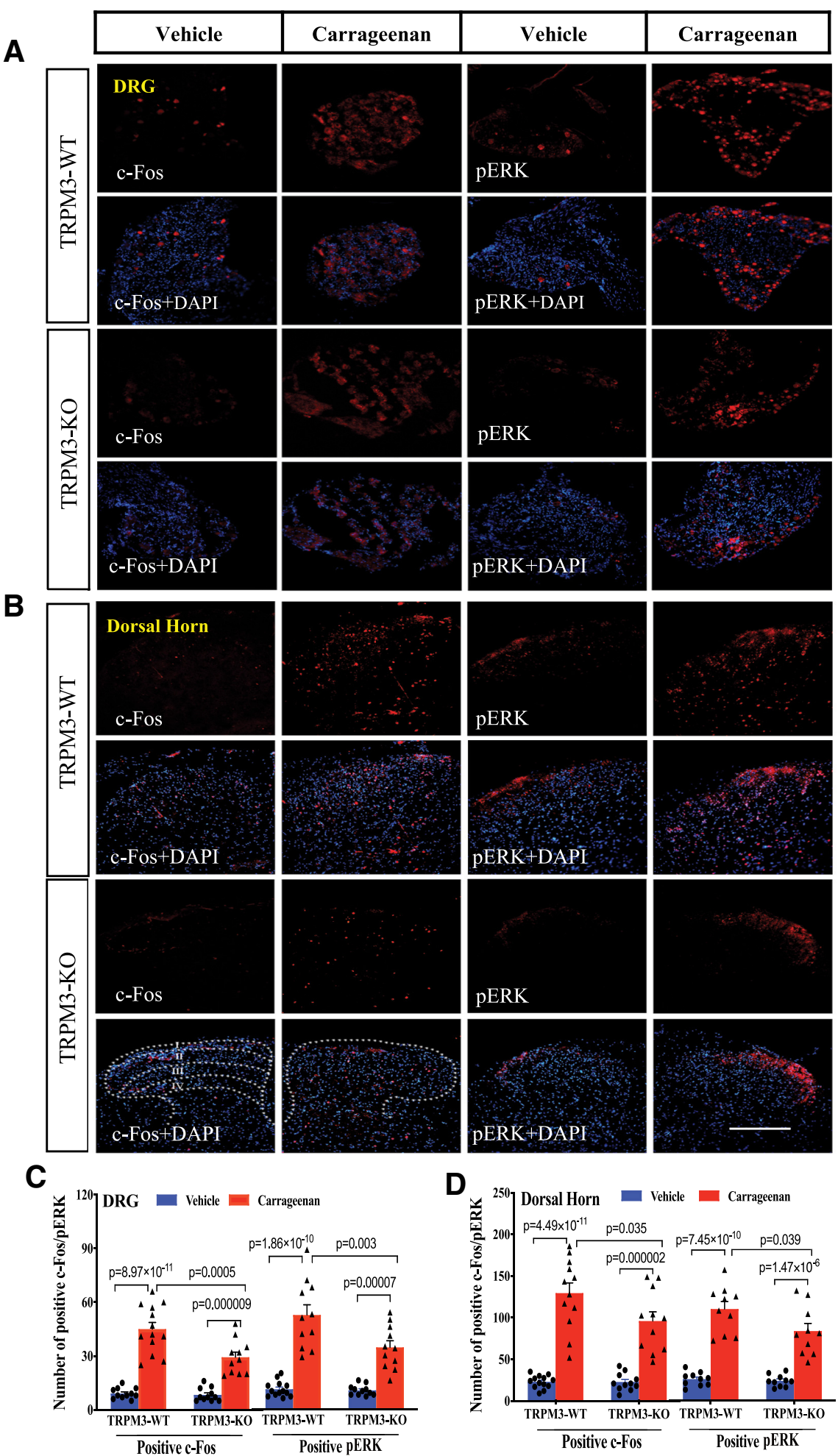

Figure 2. TRPM3 deficiency impairs carrageenan-induced pronociceptive signal transduction protein expressions in L3-L5 DRGS and the corresponding dorsal horn. $\boldsymbol{A}$, Sections of c-Fos (left) and pERK (right) immunostaining in DRGs of TRPM3-WT and TRPM3$\mathrm{KO}$ mice at $4 \mathrm{~h}$ after carrageen or vehicle injection. Scale bars, $50 \mu \mathrm{m}$. $\boldsymbol{B}$, Sections of c-Fos (left) and pERK (right) immunostaining in dorsal spinal dorsal horn of TRPM3-WT and TRPM3-KO mice at $4 \mathrm{~h}$ after carrageenan or vehicle injection. Scale bars, $50 \mu \mathrm{m}$. $\boldsymbol{C}_{t}$ The numbers of c-Fos-positive cells and pERK-positive cells in the DRG sections were counted ( $n=11-13$ sections, from three independent DRG preparations). Data are expressed as the mean \pm SEM and scatter plots. Statistical significance was calculated with two-way ANOVA (genotype $\times$ treatment) and Tukey's post hoc test $\left(F_{\text {genotype }(1,42)}=10.07, p=0.003 ; F_{\text {treatment }(1,42)}=119.29\right.$, $p=7.60 \times 10^{-14} ; F_{\text {genotype }} \times$ treatment $(1,42)=8.18, p=0.007$ for $c-$ Fos expression; $F_{\text {genotype }(1,42)}=7.77, p=0.008 ; F_{\text {treatment }(1,42)}=$ $95.04, p=2.38 \times 10^{-12} ; F_{\text {genotype } \times \text { treatment(1,42) }}=6.77, p=0.01$ for pERK expression). $\boldsymbol{D}$, The numbers of c-Fos-positive cells and pERK-positive cells in the dorsal horn sections were counted ( $n=11-13$ sections, from three independent spinal cord preparations). Statistical significance was calculated with two-way ANOVA (genotype $\times$ treatment) and Tukey's post hoc test $\left(F_{\text {genotype }(1,43)}=\right.$ sham-operated or CCI-operated animals (Fig. 3B), demonstrating that isosakuranetin reduced heat sensitivity acting on TRPM3.

We also measured paw withdrawal frequency in response to mechanical stimuli using von Frey filaments (0.07 and $0.4 \mathrm{~g})$. Figure 3, $C$ and $D$, shows that CCI surgery increased withdrawal frequency from both 0.07 and $0.4 \mathrm{~g}$ von Frey filaments in wildtype and TRPM3 ${ }^{-1-}$ mice to a similar extent, arguing against the role of TRPM3 in mechanical allodynia. Interestingly, intraperitoneal injection of $2 \mathrm{mg} / \mathrm{kg}$ isosakuranetin induced a moderate, but significant reduction in withdrawal frequency at both filament strengths in CCI-operated animals, but not in sham-operated animals. The effect of isosakuranetin, however, was similar in wild-type and in TRPM3 $3^{-1-}$ mice, indicating that its effect was not mediated by TRPM3.

Next, we tested the effect of isosakuranetin on cold sensitivity. Mice were first placed on $0^{\circ} \mathrm{C}$ cold plates (noxious cold) and the withdrawal latency was measured. Figure $3 E$ shows that wild-type CCI-operated animals showed significantly shorter withdrawal latency than sham-operated animals. Intraperitoneal injection of isosakuranetin increased the withdrawal latency in CCI-operated animals, but not in sham-operated mice. The effect of isosakuranetin was very similar in TRPM3 $^{-1-}$ mice, which indicates that isosakuranetin exerted its effect on cold sensitivity independent of TRPM3 inhibition. We also tested the number of hindpaw lifts in a 5 min period when mice were placed on a $5^{\circ} \mathrm{C}$ plate (innocuous cold). Figure $3 F$ shows that CCIoperated animals showed a substantial increase in the number of hindpaw lifts compared with sham-operated animals both in wild-type and TRPM3 $3^{-1-}$ mice. Isosakuranetin reduced the number of hindpaw lifts in both wild-type and TRPM3 ${ }^{-1-}$ CCI-operated animals to similar extents. Overall, these data indicate that isosakuranetin at $2 \mathrm{mg} / \mathrm{kg}$ inhibits cold hypersensitivity in CCI mice independently of TRPM3.

We also tested a lower dose of intraperitoneal isosakuranetin $(0.5 \mathrm{mg} / \mathrm{kg})$ on heat, mechanical, and cold sensitivity. As shown

\footnotetext{
$4.09, p=0.049, F_{\text {treatment(1,43) }}=115.29, p=9.50 \times 10^{-14}$; $F_{\text {genotype } \times \text { treatment(1,43) }}=4.00, p=0.05$ for c-Fos expression; $F_{\text {genotype(1,36) }}=4.55, p=0.04, F_{\text {treatment(1,42) }}=116.05, p=$ $8.19 \times 10^{-13 ;} F_{\text {genotype } \times \text { treatment }(1,36)}=3.31, p=0.08$ for $\mathrm{pERK}$ expression). Data are expressed as the mean \pm SEM and scatter plots.
} 
A

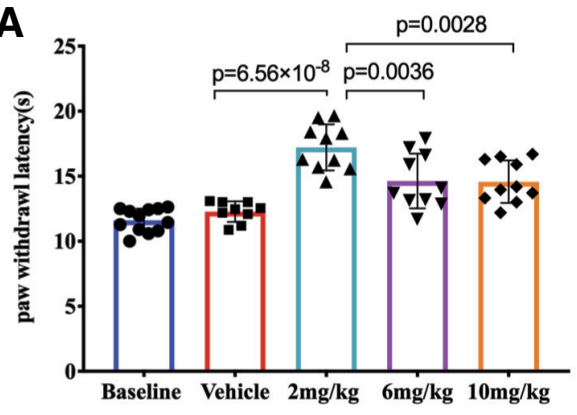

C

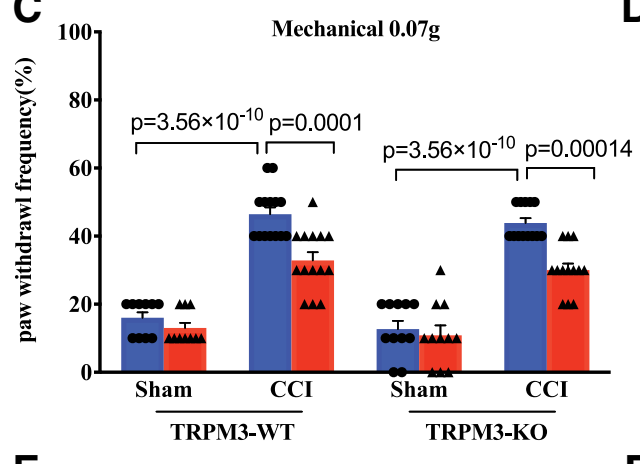

E

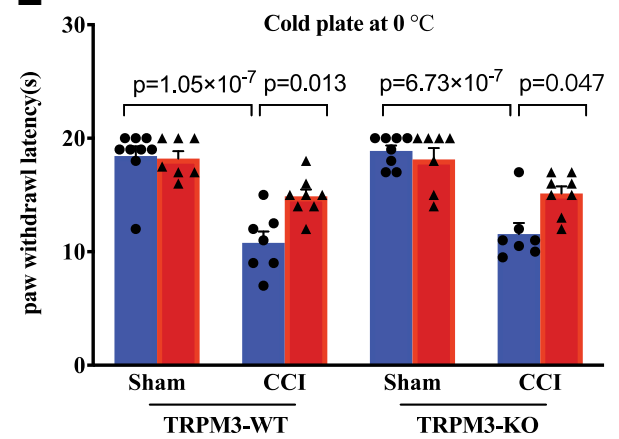

B

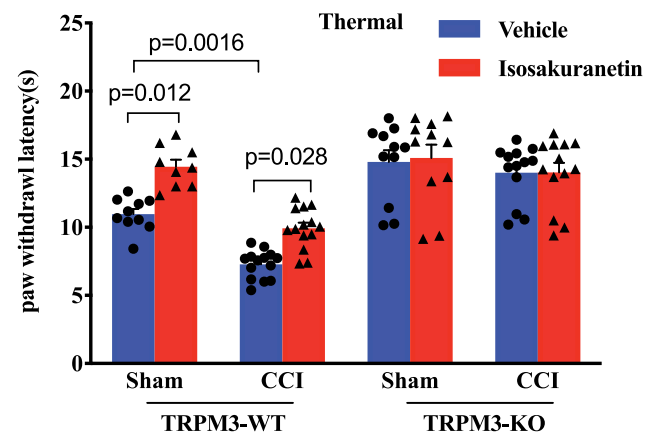

$\mathbf{D}$

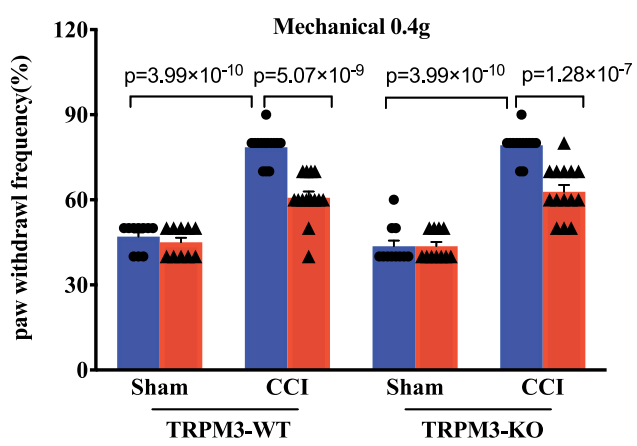

$\mathbf{F}$

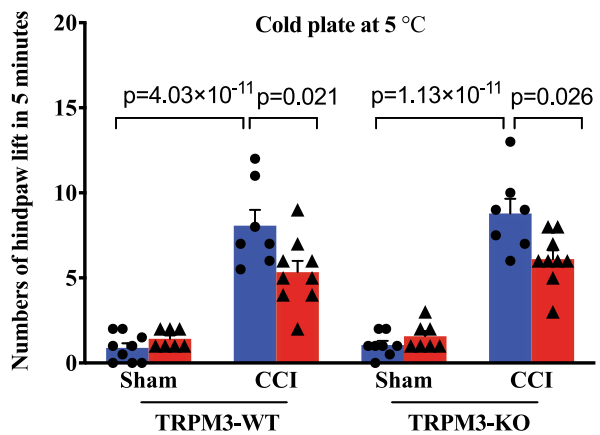

Figure 3. The effect of systemic isosakuranetin administration in naive mice and in WT and TRPM $3^{-1-}$ mice with peripheral nerve injury-induced neuropathic pain. $\boldsymbol{A}$, Paw withdrawal latencies to thermal stimuli at different doses of isosakuranetin in naive mice $(n=9-12)$; one-way ANOVA and Tukey's post hoc test $\left(F_{\text {treatment }(4,46)}=22.39, p=2.60 \times 10^{-10}\right)$. Data are expressed as the mean \pm SEM and scatter plots. $\boldsymbol{B}$, The effect of $2 \mathrm{mg} / \mathrm{kg}$ isosakuranetin on paw withdrawal latency to thermal stimuli in the Hargreaves test of ipsilateral TRPM3-WT and TRPM3-KO mice on day 6 following $\mathrm{CCl}$ or sham surgery $(n=9-14)$. The $p$ values were calculated with three-way ANOVA (surgery $\times$ genotype $\times$ treatment) and Tukey's post hoc test $\left(F_{\text {surgery }(1,87)}=32.57, p=1.56 \times 10^{-7} ; F_{\text {genotype }(1,87)}=75.63, p=1.89 \times 10^{-13} ; F_{\text {treatment }(1,87)}=13.42, p=0.0004 ; F_{\text {surgery }} \times\right.$ genotype $(1,87)=13.04, p=0.0005 ; F_{\text {surgery }} \times$ treatment $(1,87)=0.40$, $p=0.53$; $F_{\text {genotype } \times \text { treatment }(1,87)}=11.07, p=0.001$. C, $\boldsymbol{D}$, The effect of isosakuranetin on mechanical sensitivity in von Frey test of ipsilateral hindpaws of TRPM3-WT and TRPM3-K0 mice on day 6 following $C(\mathrm{Cl}$ or sham surgery at $0.07 \mathrm{~g}(\boldsymbol{C})$ and $0.4 \mathrm{~g}(\boldsymbol{D} ; n=10-14)$. Statistical significance was calculated with three-way ANOVA (surgery $\times$ genotype $\times$ treatment) and Tukey's post hoc test $\left(F_{\text {surgery }(1,88)}=280.24, p<1 \times 10^{-15} ; F_{\text {genotype }(1,88)}=3.24, p=0.08 ; F_{\text {treatment }(1,88)}=28.83, p=6.35 \times 10^{-7} ; F_{\text {surgery }} \times\right.$ genotype $(1,88)=0.0002, p=0.99 ; F_{\text {surgery }} \times$ treatment $(1,88)=$ $14.17, p=0.0003 ; F_{\text {genotype }} \times$ treatment $(1,88)=0.02, p=0.88$ for the values at $0.07 \mathrm{~g} ; F_{\text {surgery(1,88) }}=376.92, p<1 \times 10^{-15} ; F_{\text {genotype }(1,88)}=0.39, p=0.53 ; F_{\text {treatment }(1,88)}=52.32, p=1.65 \times$ $10^{-10} ; F_{\text {surgery }} \times$ genotype(1,88) $=1.43, p=0.23 ; F_{\text {surgery } \times \text { treatment }(1,88)}=41.77, p=5.53 \times 10^{-9} ; F_{\text {genotype }} \times$ treatment $(1,88)=0.17, p=0.68$ for the values at $\left.0.4 \mathrm{~g}\right) . \boldsymbol{E}, \boldsymbol{F}$, The effect of isosakuranetin on paw withdrawal responses to noxious cold $(\boldsymbol{E})$ and innocuous cold $(\boldsymbol{F})$ in cold plate test of ipsilateral of TRPM3-WT and TRPM3-KO mice on day $6 \mathrm{following} C(\mathrm{Cl}$ or sham surgery $(n=7-9)$. The $p$ values were calculated with three-way ANOVA (surgery $\times$ genotype $\times$ treatment) and Tukey's post hoc test $\left(F_{\text {surgeng( }(1,53)}=92.31, p=3.35 \times 10^{-13} ; F_{\text {genotype }(1,53)}=0.40\right.$, $p=0.53 ; F_{\text {treatment }(1,53)}=9.06, p=0.004 ; F_{\text {surgery }} \times$ genotype(1,53) $=0.09, p=0.76 ; F_{\text {surgery } \times \text { treatment }(1,53)}=15.04, p=0.0003 ; F_{\text {genotype }} \times$ treatment $(1,53)=0.22, p=0.64$ for the values at the $0^{\circ} \mathrm{C}$ plate; $F_{\text {surgery }(1,55)}=217.21, p<1 \times 10^{-15} ; F_{\text {genotype }(1,5)}=1.30, p=0.26 ; F_{\text {treatment }(1,55)}=7.59, p=0.008 ; F_{\text {surgery } \times \text { genotype }(1,55)}=0.55, p=0.46 ; F_{\text {surgery }} \times$ treatment $(1,55)=16.63$, $p=0.0001 ; F_{\text {genotype } \times \text { treatment }(1,55)}=0.0004, p=0.98$; for the values at the $5^{\circ} \mathrm{C}$ plate). Data are expressed as the mean \pm SEM and scatter plots.

in Figure 4, at this lower dose, isosakuranetin inhibited heat responses in wild-type CCI-operated mice, and while the effect was smaller than that induced by $2 \mathrm{mg} / \mathrm{kg}$, it was statistically significant. In sham-operated animals, $0.5 \mathrm{mg} / \mathrm{kg}$ induced a small, statistically nonsignificant $(p=0.29)$ increase in paw withdrawal latency in wild-type, but not in TRPM3 $3^{-1-}$ mice (Fig. $4 A$ ). On the contralateral side, $0.5 \mathrm{mg} / \mathrm{kg}$ induced only a negligible increase in paw withdrawal latency both in sham-operated and CCI-operated wild-type mice $(p=0.69$ and 0.84 ), respectively (Fig. $4 B$ ). Mechanical and cold responses were not affected by $0.5 \mathrm{mg} / \mathrm{kg}$ isosakuranetin (Fig. $4 \mathrm{C}-\mathrm{H}$ ).
Next, we tested the effects of primidone, a clinically used antiepileptic medication, which was shown to directly inhibit TRPM3 (Krügel et al., 2017). Primidone is a prodrug, and it is metabolized in the liver to the active metabolite phenobarbital, which is thought to be responsible for the antiepileptic effects (Krügel et al., 2017). Primidone was shown to decrease basal heat sensitivity as well as thermal hyperalgesia evoked by local CFA injection (Krügel et al., 2017), but its effects have not been tested in neuropathic pain. First, we tested the dose dependence of primidone on basal heat sensitivity in naive mice by injecting $0.5,1$, and $2 \mathrm{mg} / \mathrm{kg}$ primidone intraperitoneally. Figure $5 \mathrm{~A}$ shows that 
A

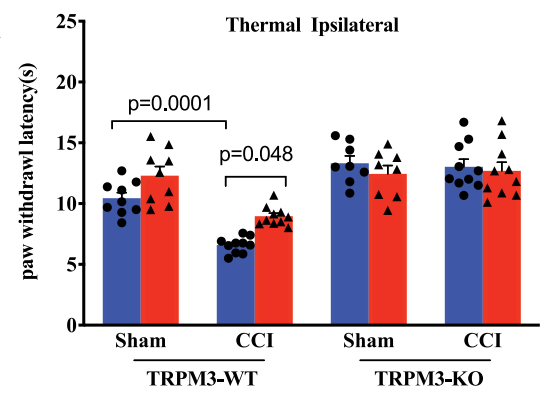

C

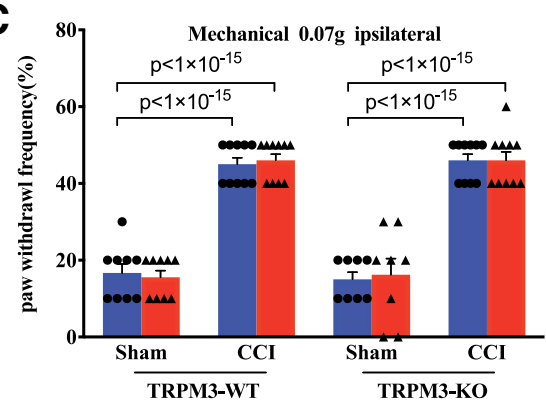

E

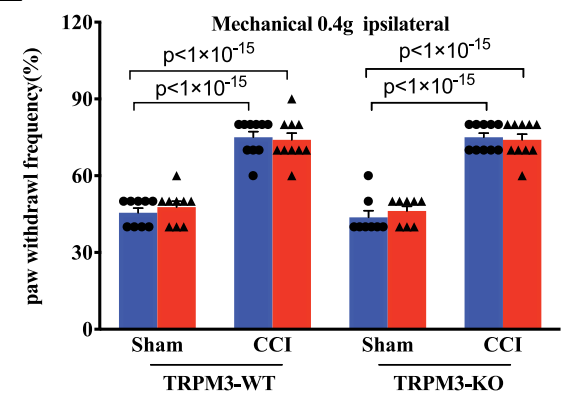

G

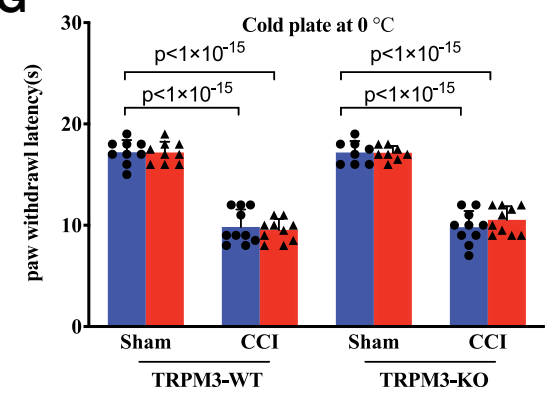

B

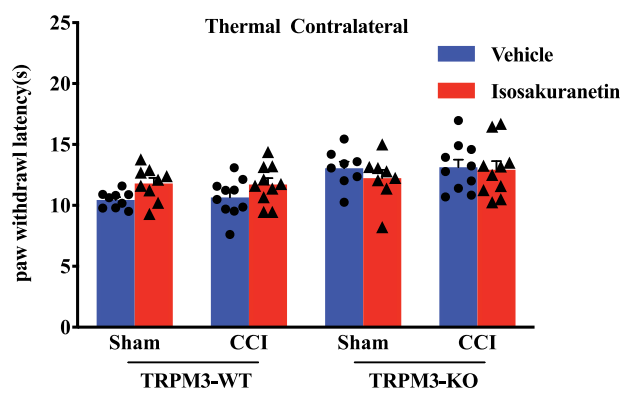

D

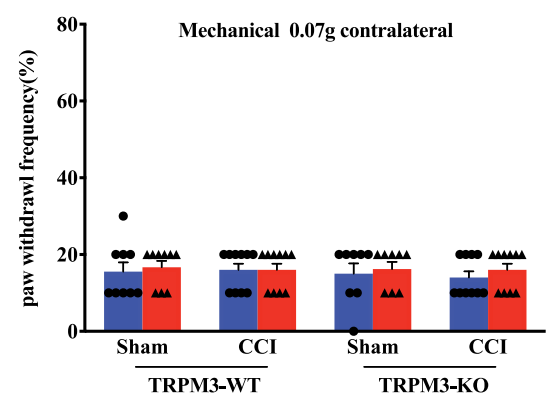

$\mathbf{F}$

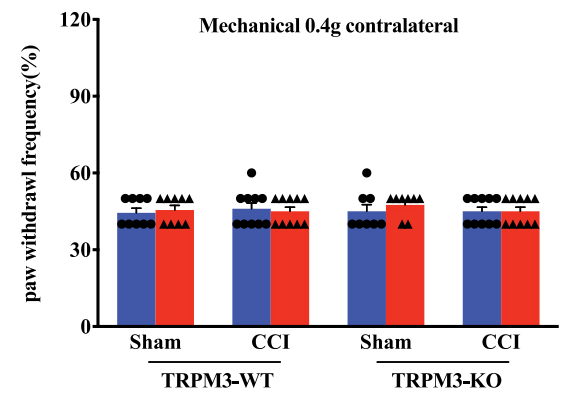

H

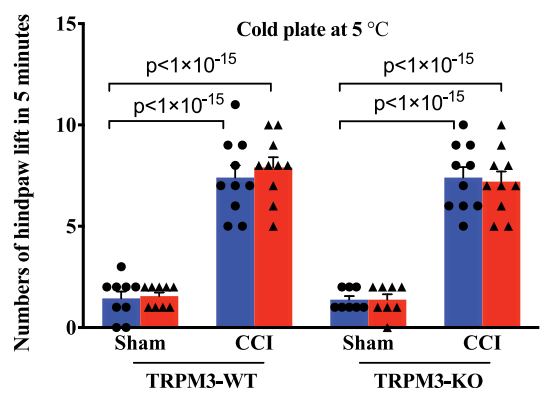

Figure 4. The effect of systemic administration of $0.5 \mathrm{mg} / \mathrm{kg}$ isosakuranetin in WT and TRPM3 ${ }^{-1-}$ mice with peripheral nerve injury-induced neuropathic pain. $A, B$, The effect of isosakuranetin on paw withdrawal latency to thermal stimuli in the Hargreaves test of ipsilateral $(\boldsymbol{A})$ and contralateral $(\boldsymbol{B})$ hindpaws of TRPM3-WT and TRPM3-K0 mice on day 6 following $C \mathrm{Cl}$ or sham surgery $(n=8-10)$; three-way ANOVA (surgery $\times$ genotype $\times$ treatment) and Tukey's post hoc test $\left(F_{\text {surgery }(1,66)}=21.16, p=2.0 \times 10^{-5} ; F_{\text {genotype }(1,66)}=70.08, p=5.73 \times 10^{-12}\right.$; $F_{\text {treatment }(1,66)}=3.64, p=0.06 ; F_{\text {surgery }} \times$ genotype $(1,66)=20.61, p=2.0 \times 10^{-5} ; F_{\text {surgery }} \times$ treatment(1,66) $=0.45, p=0.50 ; F_{\text {genotype } \times \text { treatment }(1,66)}=11.98, p=0.0009$ for the values of ipsilateral side). $\boldsymbol{C}-\boldsymbol{F}$, The effect of isosakuranetin on mechanical sensitivity in von Frey test of ipsilateral $(\boldsymbol{C}, \boldsymbol{E})$ and contralateral $(\boldsymbol{D}, \boldsymbol{F})$ hindpaws of TRPM3-WT and TRPM3-K0 mice on day 6 following $\mathrm{CCl}$ or sham surgery at $0.07 \mathrm{~g}(\boldsymbol{C}, \boldsymbol{D})$ and $0.4 \mathrm{~g}(\boldsymbol{E}, \boldsymbol{F} ; n=8-10)$; three-way ANOVA (surgery $\times$ genotype $\times$ treatment) and Tukey's post hoc test $\left(F_{\text {surgery }}(1,66)=372.0, p<1 \times 10^{-15}\right.$; $F_{\text {genotype }(1,66)}=0.04, p=0.85 ; F_{\text {treatment }(1,66)}=0.15, p=0.70 ; F_{\text {surgery } \times \text { genotype }(1,66)}=0.26, p=0.61 ; F_{\text {surgery }} \times$ treatment $(1,66)=0.004, p=0.95 ; F_{\text {genotype }} \times$ treatment $(1,66)=0.17, p=0.68$ for the values at the ipsilateral side at $0.07 \mathrm{~g} . F_{\text {surgery }(1,66)}=339.24, p<1 \times 10^{-15} ; F_{\text {genotype }(1,66)}=0.29, p=0.59 ; F_{\text {treatment }(1,66)}=0.19, p=0.66 ; F_{\text {surgery } \times \text { genotype } 1,66)}=0.29, p=0.60$; $F_{\text {surgery } \times \text { treatment }(1,66)}=1.17, p=0.28 ; F_{\text {genotype } \times \text { treatment }(1,66)}=0.002, p=0.96$ for the values at the ipsilateral side at $\left.0.4 \mathrm{~g}\right) . \mathbf{G}, \boldsymbol{H}$, The effect of isosakuranetin on paw withdrawal responses to noxious cold $(\mathbf{G})$ and innocuous cold $(\boldsymbol{H})$ in cold plate test of ipsilateral of TRPM3-WT and TRPM3-KO mice on day 6 following $\mathrm{CCl}$ or sham surgery $(n=8-10)$; three-way ANOVA (surgery $\times$ genotype $\times$ treatment) and Tukey's post hoc test $F_{\text {surgery(1,66) }}=581.58, p<1 \times 10^{-15} ; F_{\text {genotype }(1,66)}=0.54, p=0.47 ; F_{\text {treatment }(1,66)}=0.04, p=0.84 ; F_{\text {surgery }} \times$ genotype(1,66) $=0.74, p=0.39$; $F_{\text {surgery }} \times$ treatment $(1,66)=0.16, p=0.69 ; F_{\text {genotype } \times \text { treatment }(1,66)}=0.76, p=0.39$ at the $0^{\circ} \mathrm{C}$ plate; $F_{\text {surgery }(1,66)}=369.32, p<1 \times 10^{-15} ; F_{\text {genotype }(1,66)}=0.57, p=0.45 ; F_{\text {treatment }(1,66)}=0.11$, $p=0.74 ; F_{\text {surgery } \times \text { genotype }(1,66)}=0.13, p=0.72 ; F_{\text {surgery }} \times$ treatment $(1,66)=0.02, p=0.88 ; F_{\text {genotype } \times \text { treatment }(1,66)}=0.42, p=0.52$ at the $5^{\circ} \mathrm{C}$ plate). Data are expressed as the mean \pm SEM and scatter plots.

all three concentrations increased withdrawal latency to radiant heat, with $1 \mathrm{mg} / \mathrm{kg}$ showing the strongest effect; thus, we proceeded with this dose in subsequent experiments. On the ipsilateral side, intraperitoneal injection of $1 \mathrm{mg} / \mathrm{kg}$ primidone significantly increased the paw withdrawal latency in wild-type
CCI mice, but the withdrawal latency was still lower than that observed in TRPM $3^{-1-}$ mice (Fig. 5B). Primidone increased latency of paw withdrawal from radiant heat in wild-type shamoperated mice to levels similar to those observed in TRPM3 ${ }^{-1-}$ mice (Fig. $5 B$ ). In TRPM3 ${ }^{-1-}$ mice, primidone had no effect on 
A

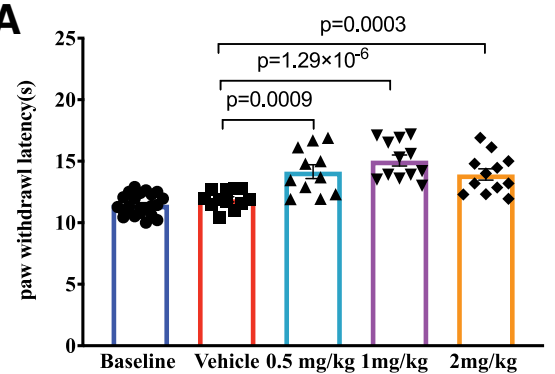

D

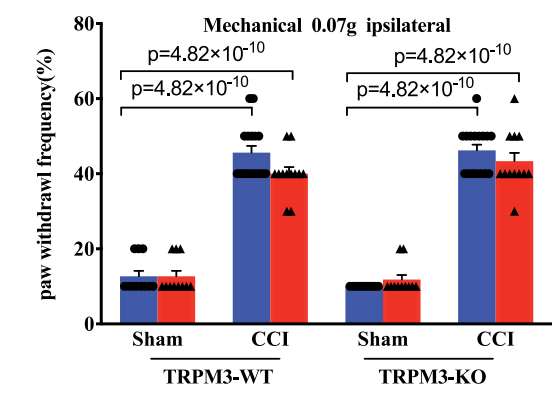

G

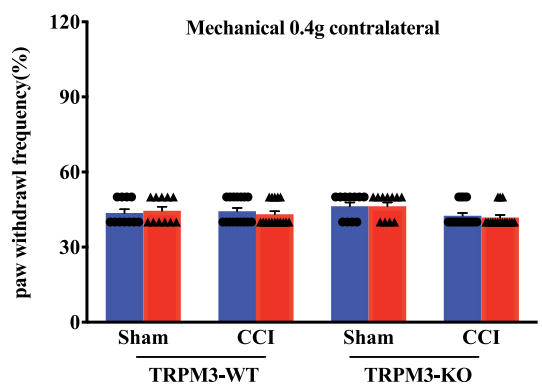

B

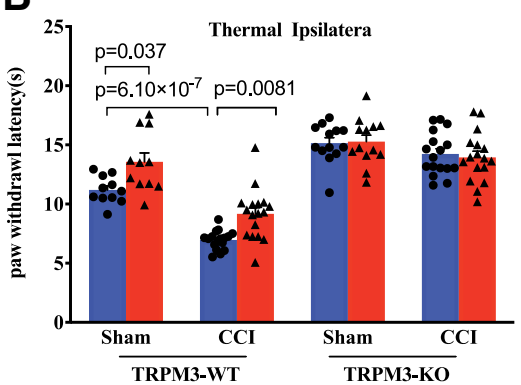

E

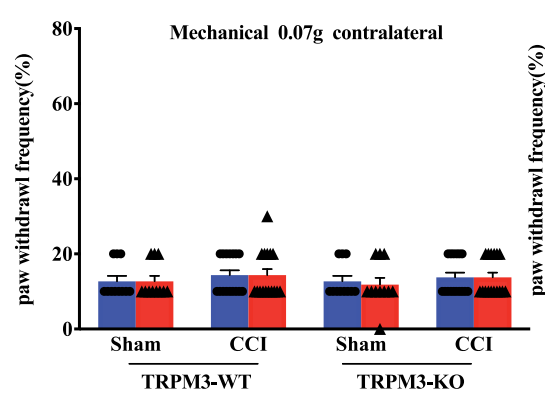

H

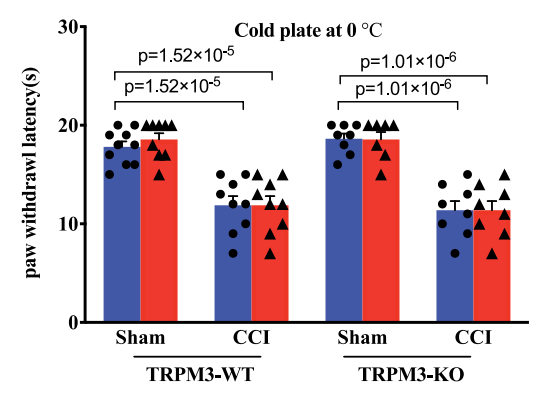

I
C

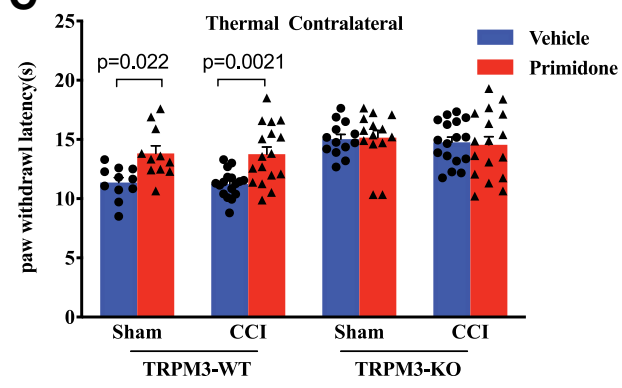

$\mathbf{F}$
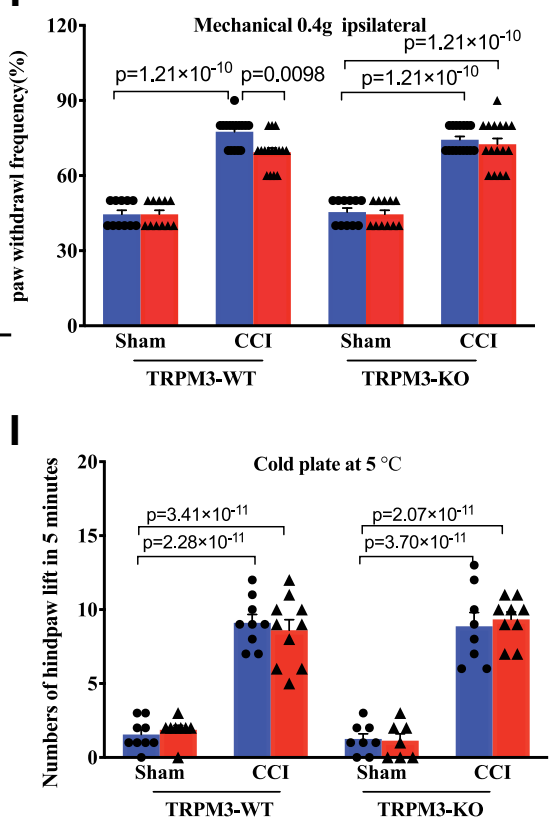

Figure 5. The effect of systemic primidone administration in naive mice and WT and TRPM3-KO mice with peripheral nerve injury-induced neuropathic pain. $\boldsymbol{A}$, Paw withdrawal latencies to thermal stimuli at different doses of primidone in naive mice $(n=11-23)$. Statistical significance was assessed by one-way ANOVA and Tukey's post hoc test $\left(F_{\text {treatment }(4,65)}=21.33\right.$, $\left.p=2.85 \times 10^{-11}\right)$. Data are expressed as the mean \pm SEM and scatter plots. $\boldsymbol{B}, \boldsymbol{C}$, The effect of primidone on paw withdrawal latencies to thermal stimuli in the Hargreaves test of ipsilateral $(\boldsymbol{B})$ and contralateral $(\boldsymbol{C})$ side in TRPM3-WT and TRPM3-KO mice on day 6 post CCl or sham surgery $(n=11-17)$. The $p$ values were calculated with three-way ANOVA (surgery $\times$ genotype $\times$ treatment) and Tukey's post hoc test $\left(F_{\text {surgery }(1,108)}=61.08, p=3.86 \times 10^{-12} ; F_{\text {genotype }(1,108)}=162.57, p<1 \times 10^{-15} ; F_{\text {treatment }(1,108)}=10.16, p=0.002 ; F_{\text {surgery }} \times\right.$ genotype $(1,108)=21.15$, $p=1.0 \times 10^{-15} ; F_{\text {surgery } \times \text { treatment }(1,108)}=0.16, p=0.69 ; F_{\text {genotype } \times \text { treatment }(1,108)}=11.59, p=0.0009$ for the values at the ipsilateral side; $F_{\text {surgery }(1,109)}=0.47, p=0.50 ; F_{\text {genotype }(1,109)}=$ $36.50, p=2.17 \times 10^{-8} ; F_{\text {treatment }(1,109)}=10.13, p=0.002 ; F_{\text {surgery } \times \text { genotype }(1,109)}=0.18, p=0.67 ; F_{\text {surgery }} \times$ treatment $(1,109)=0.03, p=0.85 ; F_{\text {genotype } \times \text { treatment }(1,109)}=10.76, p=0.001$ for the values at the contralateral side). $\boldsymbol{D}-\mathbf{G}$, The effect of primidone on paw withdrawal frequencies to mechanical stimulation in von Frey test at $0.07 \mathrm{~g}(\boldsymbol{D}$, ipsilateral; $\boldsymbol{E}$, contralateral) and $0.4 \mathrm{~g}$ $(\boldsymbol{F}$, ipsilateral; $\boldsymbol{G}$, contralateral) of TRPM3-WT and TRPM3-K0 mice on day 6 after $C(C$ or sham surgery $(n=11-16)$; three-way ANOVA (surgery $\times$ genotype $\times$ treatment) and Tukey's post hoc test $F_{\text {surgery }(1,92)}=757.02, p<1 \times 10^{-15} ; F_{\text {genotype }(1,92)}=0.005, p=0.94 ; F_{\text {treatment }(1,92)}=2.09, p=0.15 ; F_{\text {surgery }} \times$ genotype(1,92) $=2.67, p=0.11 ; F_{\text {surgery }} \times$ treatment $(1,92)=4.96, p=0.03$; $F_{\text {genotype } \times \text { treatment }(1,92)}=0.95, p=0.33$ for the values of ipsilateral side at $0.07 \mathrm{~g} ; F_{\text {surgery }(1,100)}=538.51, p<1 \times 10^{-15} ; F_{\text {genotype }(1,100)}=0.03, p=0.85 ; F_{\text {treatment }(1,100)}=4.87, p=0.03$; $F_{\text {surgery } \times \text { genotype }(1,100)}=0.03, p=0.85 ; F_{\text {surgery } \times \text { treatment }(1,100)}=3.39, p=0.07 ; F_{\text {genotype } \times \text { treatment }(1,100)}=1.17, p=0.28$ for the values at the ipsilateral side at $0.4 \mathrm{~g}$. $\boldsymbol{H}, \boldsymbol{I}$, The effect of primidone on paw withdrawal responses to noxious cold $(\boldsymbol{H})$ and innocuous cold $(\boldsymbol{I})$ in cold plate test at the ipsilateral side of TRPM3-WT and TRPM3-K0 mice on day 6 post CCl or sham surgery $(n=7-10)$. P values were calculated with three-way ANOVA (surgery $\times$ genotype $\times$ treatment) and Tukey's post hoc test $\left(F_{\text {surgery }(1,60)}=145.35, p<1 \times 10^{-15} ; F_{\text {genotype }(1,60)}=0.007\right.$, $p=0.93 ; F_{\text {treatment }(1,60)}=0.10, p=0.76 ; F_{\text {surgery } \times \text { genotype }(1,60)}=0.70, p=0.41 ; F_{\text {surgery } \times \text { treatment }(1,60)}=0.10, p=0.76 ; F_{\text {genotype } \times \text { treatment }(1,60)}=0.13, p=0.72$ in noxious cold testing; $F_{\text {surgery }(1,60)}=340.86, p<1 \times 10^{-15} ; F_{\text {genotype }(1,60)}=0.11, p=0.74 ; F_{\text {treatment }(1,60)}=0.01, p=0.92 ; F_{\text {surgery }} \times$ genotype $(1,60)=0.89, p=0.35 ; F_{\text {surgery }} \times$ treatment $(1,60)=0.03, p=0.87$; $F_{\text {genotype } \times \text { treatment }(1,60)}=0.11, p=0.74$ in innocuous cold testing). Data are expressed as the mean \pm SEM and scatter plots.

paw withdrawal latency in either sham-operated or CCI-operated mice (Fig. 5B). On the contralateral side, animals that had undergone CCI surgery displayed no increase in heat sensitivity compared with sham-operated animals, and primidone increased withdrawal latency both in CCI-operated and shamoperated wild-type animals, but not TRPM3 ${ }^{-1-}$ animals (Fig. $5 C$ ). These data show that primidone reduces heat sensitivity in both naive and neuropathic animals by inhibiting TRPM3.

Next, we tested the effect of primidone on mechanical sensitivity using von Frey filaments (Fig. 5D-G). Both CCI-operated wild-type and $\mathrm{TRPM}^{-1-}$ animals displayed increased withdrawal frequency to both $0.07 \mathrm{~g}$ (Fig. 5D) and $0.4 \mathrm{~g}$ (Fig. 5F) filaments compared with sham-operated animals. Intraperitoneal injection of primidone had no effect on paw withdrawal frequency in sham-operated animals either in wild-type or in TRPM3 ${ }^{-/-}$mice at $0.07 \mathrm{~g}$ (Fig. 5D) and $0.4 \mathrm{~g}$ (Fig. 5F). Primidone induced a small, statistically not significant decrease in paw withdrawal frequency at $0.07 \mathrm{~g}$ both in wild-type mice $(p=0.17)$ and in TRPM3 ${ }^{-1-}$ CCI-operated mice $(p=0.17$; Fig. $5 D)$. At $0.4 \mathrm{~g}$, primidone induced a small, but statistically significant decrease in wild-type mice, but not in TRPM $3^{-1-}$ mice (Fig. $4 F)$. On the contralateral side, CCI surgery did not increase mechanical sensitivity, and primidone had no effect on mechanical sensitivity (Fig. 5E,G). 
A

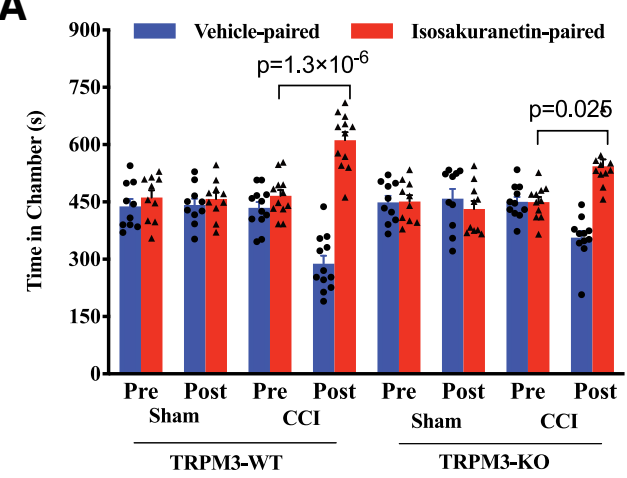

C

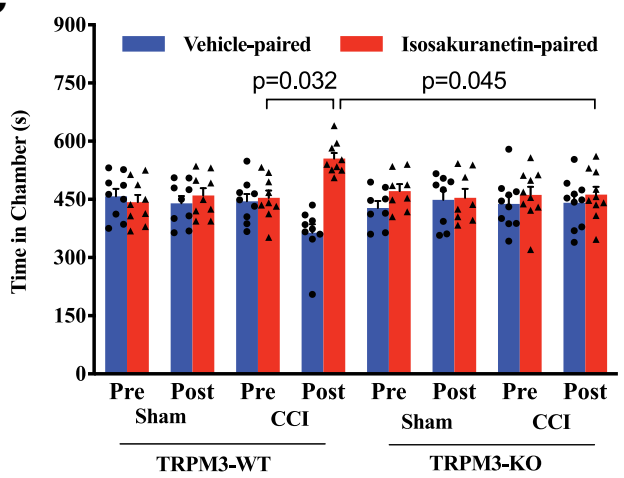

B

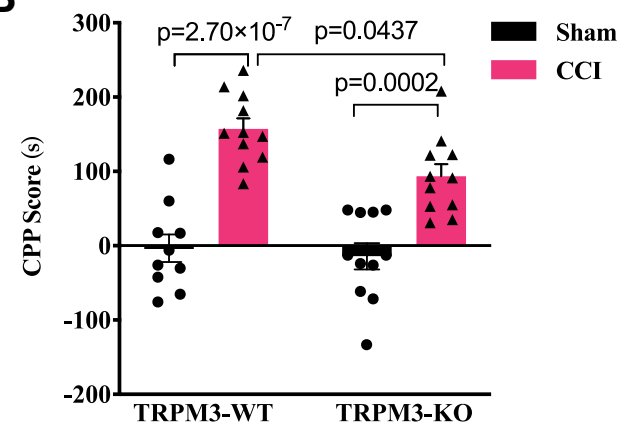

D

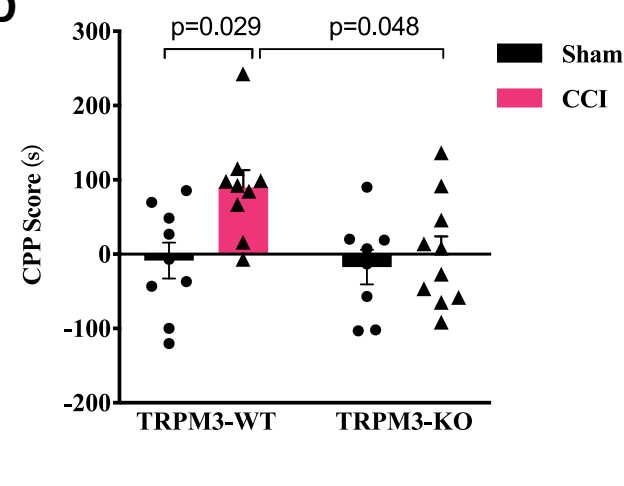

Figure 6. Systemic administration of isosakuranetin alleviates spontaneous pain in WT and TRPM3-KO mice following CCI surgery in the CPP test. CPP experiments were performed as described in the Materials and Methods section. A, Time spent in the chamber paired with vehicle or isosakuranetin $(2 \mathrm{mg} / \mathrm{kg})$ in TRPM3-WT and TRPM3-K0 mice in the sham-operated and C(l-operated groups $(n=10-12)$. The $p$ values were calculated using three-way ANOVA (condition $\times$ genotype $\times$ treatment) and Tukey's post hoc test $\left(F_{\text {condition }(3,156)}=\right.$ $0.02, p=0.99 ; F_{\text {genotype }(1,156)}=0.02, p=0.89 ; F_{\text {treatment }(1,156)}=58.73, p=1.80 \times 10^{-12} ; F_{\text {condition }} \times$ genotype(3,156) $=0.02, p=0.99 ; F_{\text {condition }} \times$ treatment(3,156) $=49.28, p<1 \times 10^{-15}$; $F_{\text {genotype }} \times$ treatment $(1,156)=10.22, p=0.002$. B, CPP score was calculated as described in the Materials and Methods section for TRPM3-WT and TRPM3-KO mice in the sham-operated and CCloperated groups $(n=10-12)$. The $p$ values were calculated using two-way ANOVA (genotype $\times$ surgery) and Tukey's post hoc test $\left(F_{\text {genotype }(1,39)}=5.00, p=0.03 ; F_{\text {surgery }(1,39)}=65.33\right.$, $p=7.35 \times 10^{-10} ; F_{\text {genotype }} \times$ surgery $(1.39)=2.54, p=0.12$ ). Data are expressed as the mean \pm SEM and scatter plots. $\boldsymbol{C}, \boldsymbol{D}$, similar measurements in mice injected with $0.5 \mathrm{mg} / \mathrm{kg}$ isosakuranetin. C, Time spent in corresponding chamber paired with vehicle or isosakuranetin $(0.5 \mathrm{mg} / \mathrm{kg})$ in TRPM3-WT and TRPM3-KO mice in the sham-operated and C(l-operated groups $(n=$ 8-10). The $p$ values were calculated using three-way ANOVA (condition $\times$ genotype $\times$ treatment) and Tukey's post hoc test $\left(F_{\text {condition }(3,128)}=0.09, p=0.97 ; F_{\text {genotype }(1,128)}=0.03, p=0.87\right.$;

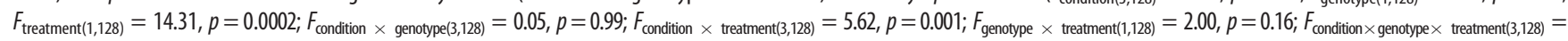
$6.57, p=0.0004)$. $\boldsymbol{D}$, (PP score was calculated as described in the Materials and Methods section for TRPM3-WT and TRPM3-KO mice in the sham-operated and C(I-operated groups $(n=8-10)$. The $p$ values were calculated using two-way ANOVA (genotype $\times$ surgery) and Tukey's post hoc test $\left(F_{\text {genotype }(1,32)}=4.25, p=0.047 ; F_{\text {surgery }(1,32)}=6.03, p=0.02 ; F_{\text {genotypex surgen }(1,32)}=2.85, p=0.10\right)$. Data are expressed as the mean \pm SEM and scatter plots.

Next, we tested the effect of primidone on cold sensitivity. Mice were first placed on a $0^{\circ} \mathrm{C}$ cold plate, and the withdrawal latency was measured. Figure $5 \mathrm{H}$ shows that both wild-type and TRPM $^{-1-}$ CCI-operated animals showed significantly shorter withdrawal latency than sham-operated animals. Intraperitoneal injection of $1 \mathrm{mg} / \mathrm{kg}$ primidone did not have any effect on the withdrawal latency in wild-type and $\mathrm{TRPM}^{-1-}$ mice. We also tested the number of hindpaw lifts when mice were placed on a $5^{\circ} \mathrm{C}$ cold plate. Figure $5 \mathrm{I}$ shows that both wild-type and TRPM $^{-1-}$ CCI-operated mice showed a substantial increase in the number of hindpaw lifts compared with sham-operated animals. Primidone injection had no effect on the number of paw lifts in wild-type and $\mathrm{TRPM}^{-1-}$ mice.

TRPM3 plays a role in spontaneous pain in nerve injuryinduced neuropathy

Next, we tested the effect of systemic TRPM3 inhibition on spontaneous pain in the CCI model using the two-chamber CPP assay (Tappe-Theodor and Kuner, 2014). The half-life of unmodified primidone is 10-12 $\mathrm{h}$ (Glazko, 1975), and the CPP assay requires repeated injections of the drug (for details, see Materials and Methods); therefore, we used intraperitoneal injection of the short-acting isosakuranetin ( 2 and $0.5 \mathrm{mg} / \mathrm{kg})$, the effect of which dissipates in 60-75 min (Straub et al., 2013; Jia et al., 2017). Figure $6, A$ and $B$, shows that wild-type CCI-operated, but not sham-operated animals, showed a significant preference for the chamber associated with $2 \mathrm{mg} / \mathrm{kg}$ isosakuranetin administration. $\mathrm{TRPM}^{-1-}$ mice also showed a preference for the chamber associated with isosakuranetin, but the extent of this preference (CPP index) was significantly lower compared with wild-type animals (Fig. 6B). When mice were injected with $0.5 \mathrm{mg} / \mathrm{kg}$ isosakuranetin, wild-type mice, but not TRPM $3^{-1-}$ mice, showed a preference for the chamber paired with the administration of the drug (Fig. $6 C, D$ ). The level of preference evoked by $0.5 \mathrm{mg} / \mathrm{kg}$ isosakuranetin was smaller than that induced by $2 \mathrm{mg} / \mathrm{kg}$. These data suggest that isosakuranetin reduces spontaneous pain in mice that had undergone CCI surgery, and the effect involves both TRPM3-dependent and TRPM3-independent mechanisms at $2 \mathrm{mg} / \mathrm{kg}$, but fully dependent on TRPM3 at $0.5 \mathrm{mg} / \mathrm{kg}$.

Next, we tested levels of c-Fos and pERK, indicators of neural activity, in DRGs and spinal dorsal horn in CCI-operated and sham-operated animals $6 \mathrm{~d}$ after the operation. Figure 7 shows that the number of c-Fos- and pERK-positive cells increased in the L3-L5 DRGs of CCI-operated animals compared with sham- 

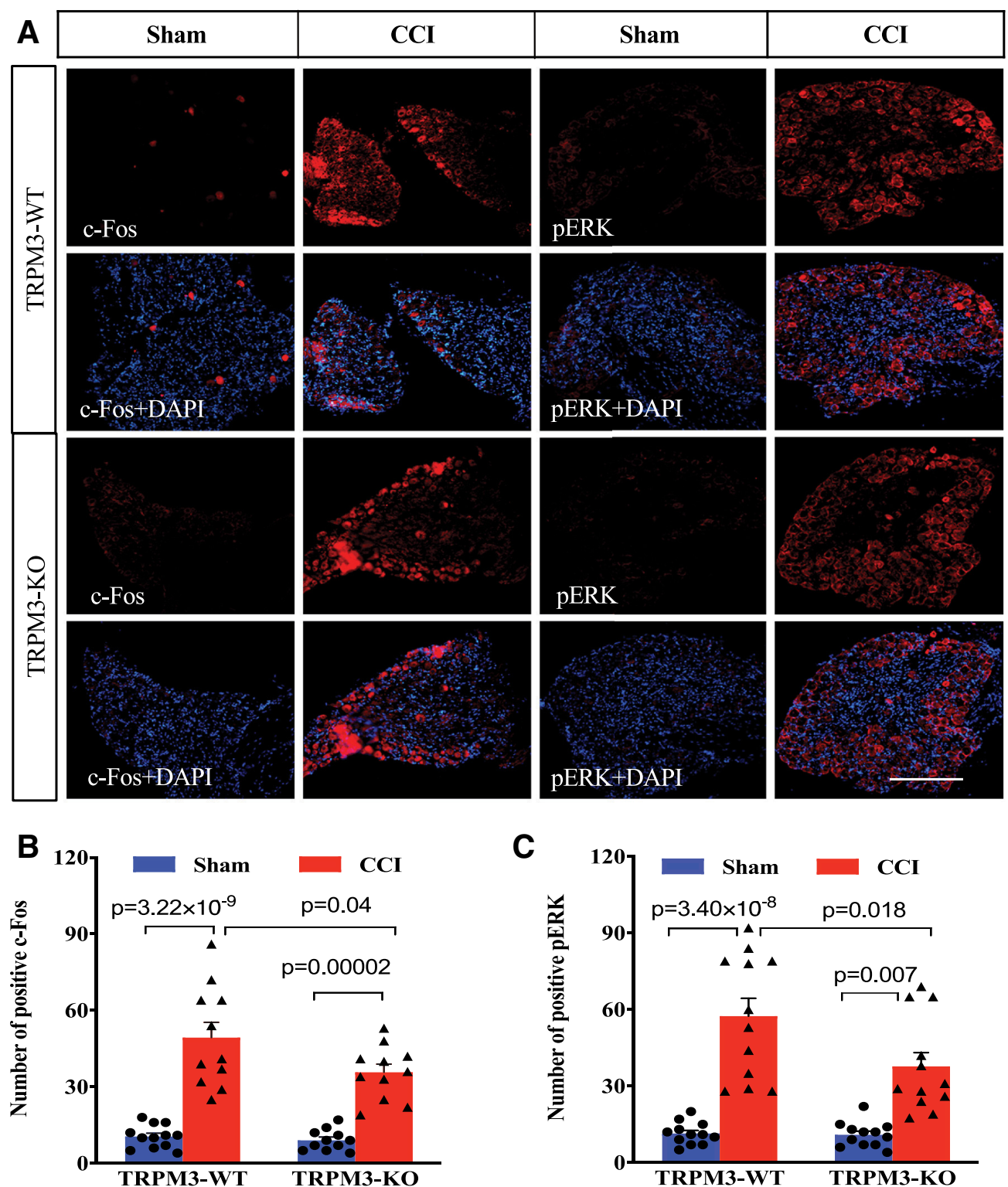

Figure 7. TRPM3 deficiency impairs pronociceptive signal transduction following CCI surgery in L3-L5 DRGs. A, Sections of c-Fos (left) and pERK (right) immunostaining in DRGs of TRPM3WT and TRPM3-KO mice on day 6 after $\mathrm{CCl}$ or sham surgery. Scale bars, $50 \mu \mathrm{m}$. $\boldsymbol{B}$, The numbers of c-Fos-positive cells in the sections were counted $(n=11-12$ sections from three independent preparations). The $p$ values were calculated with two-way ANOVA (genotype $\times$ surgery) with Tukey's post hoc test $\left(F_{\text {genotype(1.41) }}=4.77, p=0.035 ; F_{\text {surgery(1.41) }}=90.40, p=6.31 \times 10^{-12}\right.$; $F_{\text {genotype }} \times$ surgery $\left.(1,41)=3.15, p=0.08\right)$. C, The numbers of pERK-positive cells in the sections were counted ( $n=12$ sections from three independent preparations). The $p$ values were calculated with two-way ANOVA (genotype $\times$ surgery) with Tukey's post hoc test $\left(F_{\text {genotype }(1,44)}=4.97, p=0.03, F_{\text {surgery }(1,44)}=65.14, p=3.19 \times 10^{-10} ; F_{\text {genotype }} \times\right.$ surgery(1,44) $\left.=4.49, p=0.04\right)$ Data are expressed as the mean \pm SEM and scatter plots.

operated wild-type animals. In TRPM3 ${ }^{-1-}$ DRGs, c-Fos and pERK also showed an increase, but it was smaller than those in wild-type animals (Fig. $7 B, C$ ). These data indicate that TRPM3 plays a role in the increased neuronal activity in DRG neurons after CCI operation.

In the dorsal horn of the spinal cord, c-Fos and pERK levels also increased both in wild-type and TRPM3 ${ }^{-1-}$ mice $6 \mathrm{~d}$ after the CCI operation (Fig. $8 A-D$ ), but the increase in TRPM3 ${ }^{-1-}$ mice was smaller both for c-Fos (Fig. $8 C$ ) and for pERK (Fig. 8D). Intraperitoneal injection of $2 \mathrm{mg} / \mathrm{kg}$ isosakuranetin or $1 \mathrm{mg} / \mathrm{kg}$ primidone reduced the increase in c-Fos (Fig. $8 C$ ) and pERK (Fig. 8D) in wild-type animals. In TRPM3 ${ }^{-1-}$ mice, isosakuranetin, but not primidone, induced a significant decrease in the number of c-Fospositive (Fig. 8C) and pERK-positive (Fig. 8D) cells. These data indicate that TRPM3 plays a role in the increased neuronal activity in the dorsal horn in CCI-operated mice.

\section{Both intraplantar and intrathecal injection of primidone} reduce heat sensitivity

Our data with systemic injection of TRPM3 inhibitors so far show that TRPM3 is important for sensing heat, potentially important for mechanical stimuli, but not important for cold stimuli. Next, we tested whether local inhibition of TRPM3 is sufficient for reducing heat sensitivity. To this end, we injected $2.3 \mathrm{nmol}(0.5 \mu \mathrm{g})$ primidone in the hindpaw, which is one-fortieth of the dose $(1 \mathrm{mg} / \mathrm{kg})$ injected intraperitoneally for a $20 \mathrm{~g}$ mouse. At this low dose, primidone increased the latency of withdrawal to radiant heat in naive wild-type mice in the injected paw (Fig. 9A), but not in the contralateral paw (Fig. 9B), indicating that the effect was local, and not systemic.

Next, we tested the effect of intraplantar injection of the same low dose of primidone in the CCI model. Figure $9 C$ shows that primidone increased the latency of withdrawal from radiant heat 
A

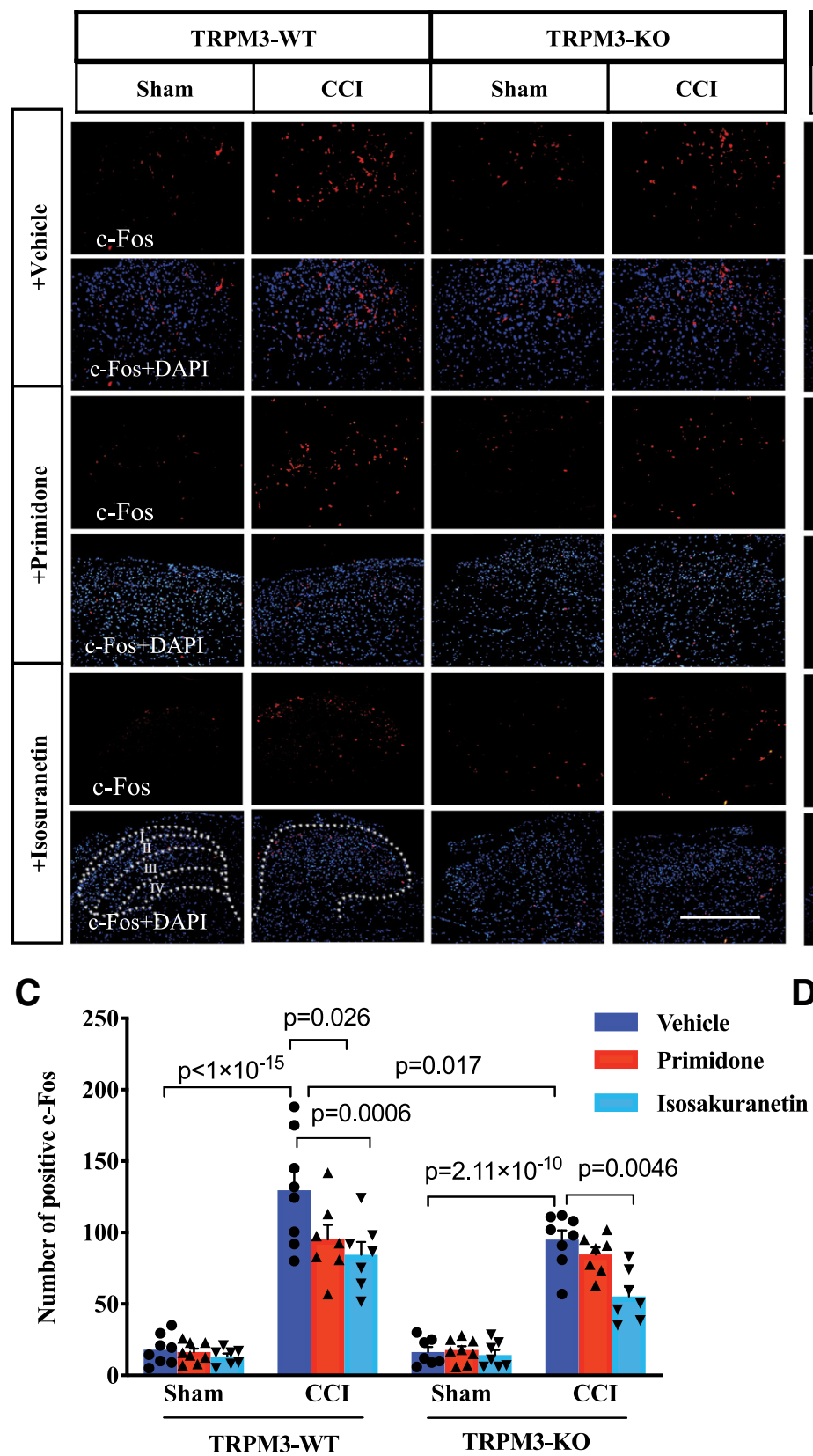

D
B

\begin{tabular}{|l|l|l|l|}
\hline \multicolumn{2}{|c|}{ TRPM3-WT } & \multicolumn{2}{c|}{ TRPM3-KO } \\
\hline Sham & CCI & Sham & CCI \\
\hline
\end{tabular}


pERK
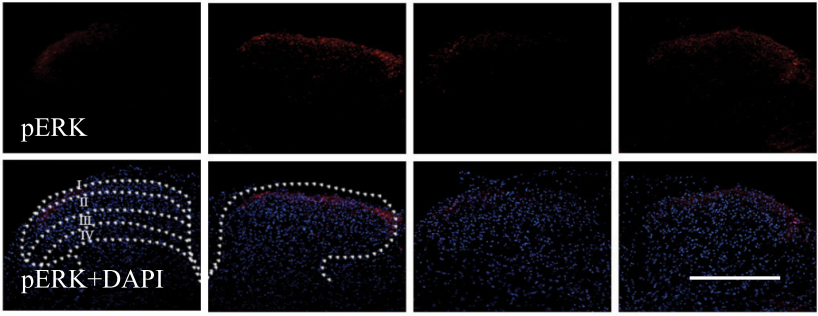

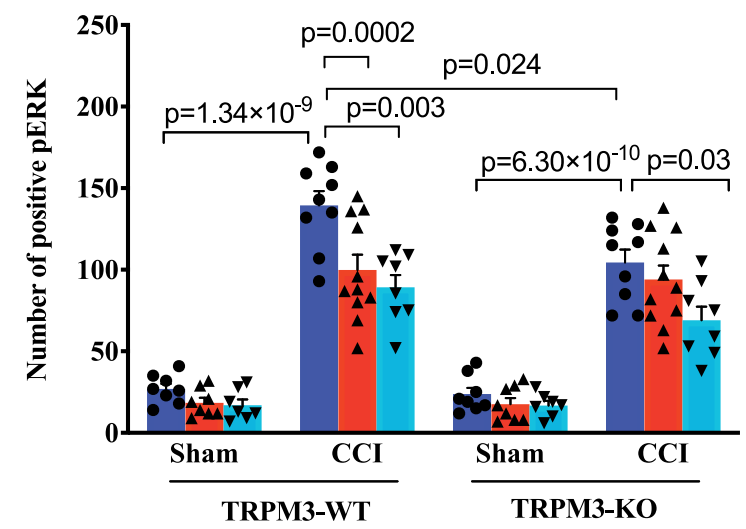

Figure 8. The effect of isosakuranetin and primidone on pronociceptive signal transduction protein levels in dorsal spinal cord on day 6 following $\mathrm{CCl}$ or sham surgery. $\boldsymbol{A}, \boldsymbol{B}$, Sections of c-Fos (left, $\boldsymbol{A}$ ) and pERK (right, $\boldsymbol{B}$ ) in L3-L5 dorsal spinal cord of TRPM3-WT and TRPM3-KO mice injected intraperitoneally with vehicle, $2 \mathrm{mg} / \mathrm{kg}$ isosakuranetin, or $1 \mathrm{mg} / \mathrm{kg}$ primidone. Scale bars, $50 \mu \mathrm{m}$. C, $\boldsymbol{D}$, The number of $\mathrm{c}$-Fos-positive cells $(\boldsymbol{C})$ and pERK-positive cells $(\boldsymbol{D})$ in the sections were counted ( $n=7-11$ sections from three independent preparations). The $p$ values were calculated with three-way ANOVA (surgery $\times$ genotype $\times$ treatment) with Tukey's post hoc test $\left(F_{\text {surgery }(1,77)}=359.66, p<1 \times 10^{-15} ; F_{\text {genotype }(1,77)}=9.68, p=0.003 ; F_{\text {treatment }(2,77)}=11.27\right.$, $p=5.09 \times 10^{-5} ; F_{\text {surgery } \times \text { genotype }(1,77)}=10.22, p=0.002 ; F_{\text {surgery }} \times$ treatment $(2,77)=8.24, p=0.0006 ; F_{\text {genotype }} \times$ treatment $(2,77)=1.03, p=0.36$ for $c-$ Fos expression; $F_{\text {surgery }(1,90)}=369.90$, $p<1 \times 10^{-15} ; F_{\text {genotype }(1,90)}=6.98, p=0.01 ; F_{\text {treatment }(2,90)}=12.77, p=1.32 \times 10^{-5} ; F_{\text {surgery }} \times$ genotype $(1,90)=5.28, p=0.02 ; F_{\text {surgery }} \times$ treatment $(2,90)=5.54, p=0.005 ; F_{\text {genotype }} \times$ treatment $(2,90)=1.29, p=0.28$ for pERK expression). Data are expressed as the mean \pm SEM and scatter plots.

both in CCI- and sham-operated wild-type animals, and it had no effect in $\mathrm{TRPM}^{-1-}$ mice. In the contralateral paw, primidone had no effect (Fig. 9D). Local injection of primidone had no effect on withdrawal from mechanical stimuli in the von Frey assay $(0.07$ and $0.4 \mathrm{~g})$ in CCI- or sham-operated wild-type and TRPM $^{-1-}$ mice (Fig. 9E-H).

TRP channels are not only expressed in the peripheral nerve endings, but also in the cell bodies and the central termini of DRG neurons (Kim et al., 2014). TRPM3 was also detected in the spinal cord with RT-PCR (Lee et al., 2003). Here we performed fluorescence in situ hybridization (RNAscope) and confirmed the expression of TRPM3 in the spinal dorsal horn. Figure 10A$E$ shows experiments with probes for TRPM3, the neuronal marker NeuN (RbFox3), and the glial marker glial fibrillary acidic protein (GFAP) in the spinal dorsal horn. Consistent with earlier data (Cao et al., 2015a; Guo et al., 2017), the proportion of GFAP-positive cells increased after CCI (Fig. 10E). TRPM3 was expressed in $74.3 \%$ of NeuN-positive cells in the CCI-operated side and $77.9 \%$ of NeuN-positive cells on the sham-operated side. TRPM3 was expressed in 34.3\% of GFAP-positive cells on 
A
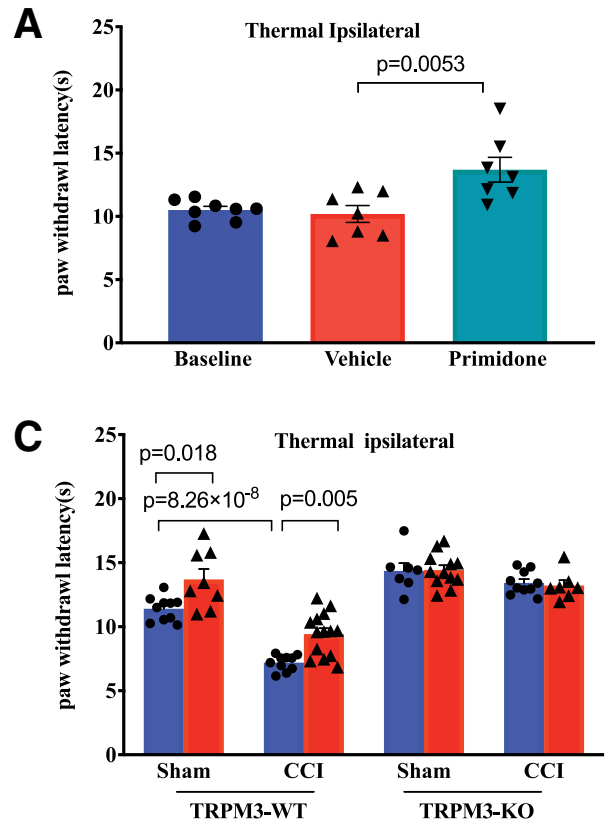

E

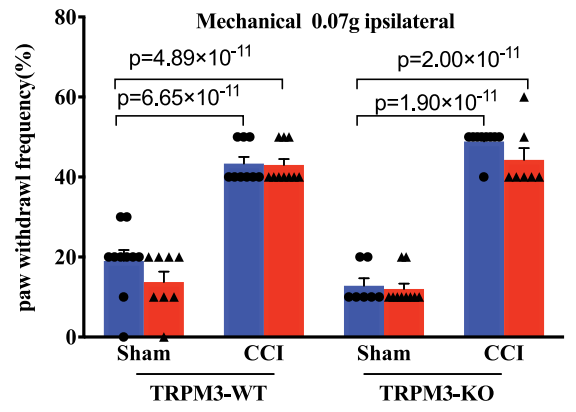

G

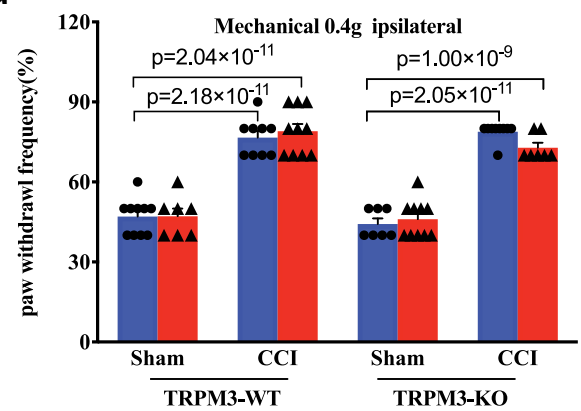

B

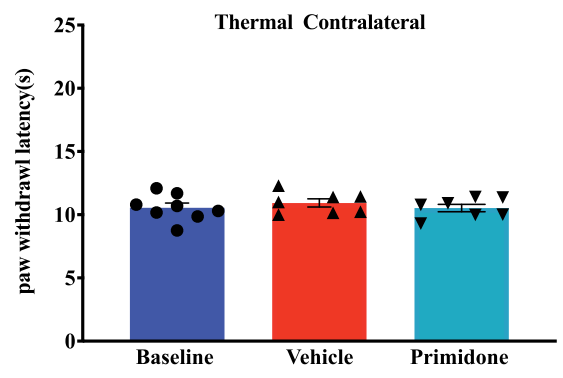

D



$\mathbf{F}$

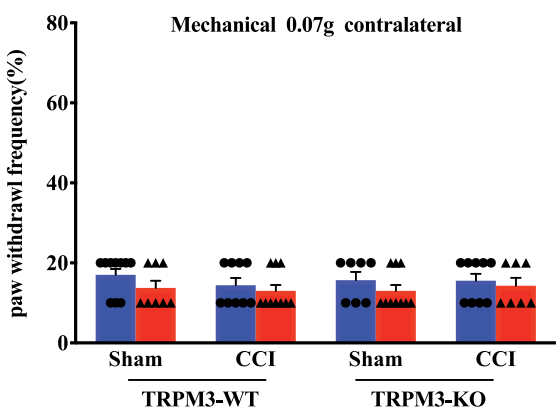

H

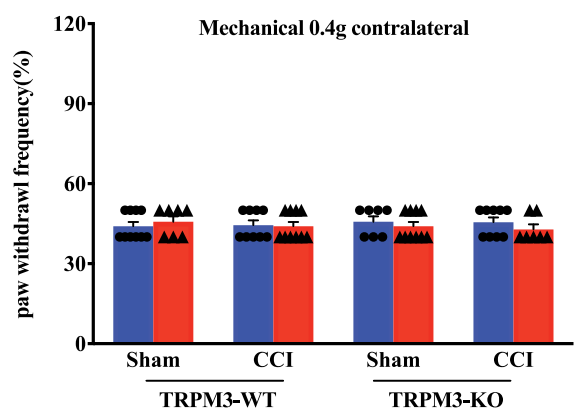

Figure 9. The effect of intraplantar primidone administration in naive mice and WT and TRPM3-KO mice with peripheral nerve injury-induced neuropathic pain. $\boldsymbol{A}$, $\boldsymbol{B}$, The effect of primidone on paw withdrawal latency to thermal stimuli in the Hargreaves test of the ipsilateral $(\boldsymbol{A})$ and contralateral $(\boldsymbol{B})$ paws in naive mice $(n=7-8)$. Statistical significance was calculated with oneway ANOVA with Tukey's post hoc test $\left(F_{\text {treatment }(2,19)}=8.00, p=0.003\right)$. Data are expressed as the mean \pm SEM and scatter plots. $\boldsymbol{C}, \boldsymbol{D}$, The effect of primidone on paw withdrawal latency to thermal stimuli in the Hargreaves test in ipsilateral $(\boldsymbol{C})$ and contralateral $(\boldsymbol{D})$ side of TRPM3-WT and TRPM3-K0 mice on day 6 after $C(C)$ or sham surgery $(n=7-12)$. Statistical significance was calculated with three-way ANOVA (surgery $\times$ genotype $\times$ treatment) and Tukey's post hoc test $\left(F_{\text {surgery }(1,70)}=67.64, p=7.05 \times 10^{-12} ; F_{\text {genotype }(1,70)}=113.01, p<1 \times 10^{-15} ; F_{\text {treatment }}\right.$ $(1,70)=11.63, p=0.001 ; F_{\text {surgery } \times \text { genotype }(1,70)}=24.08, p=5.80 \times 10^{-5} ; F_{\text {surgery } \times \text { treatment }(1,70)}=0.07, p=0.79 ; F_{\text {genotype } \times \text { treatment }(1,70)}=13.19, p=0.0005$ for the values at the ipsilateral side). $\boldsymbol{E}-\boldsymbol{H}$, The effect of primidone on paw withdrawal frequency to mechanical stimulation in the von Frey test at $0.07 \mathrm{~g}(\boldsymbol{E}$, ipsilateral; $\boldsymbol{F}$, contralateral) and $0.4 \mathrm{~g}(\boldsymbol{G}$, ipsilateral; $\boldsymbol{H}$, contralateral) of TRPM3-WT and TRPM3-K0 mice on day 6 after $\mathrm{CCl}$ or sham surgery $(n=7-10)$. Statistical significance was calculated with three-way ANOVA (surgery $\times$ genotype $\times$ treatment) with Tukey's post hoc test $\left(F_{\text {surgery }(1,62)}=438.77, p<1 \times 10^{-15} ; F_{\text {genotype }(1,62)}=0.03, p=0.86 ; F_{\text {treatment }(1,62)}=3.60, p=0.06 ; F_{\text {surgery } \times \text { genotype }(1,62)}=6.41, p=0.01 ; F_{\text {surgery }} \times\right.$ treatment $(1,62)=$ $0.04, p=0.84 ; F_{\text {genotype } \times \text { treatment }(1,62)}=0.0004, p=0.98$ for the values at the ipsilateral side at $0.07 \mathrm{~g} ; F_{\text {surgery }(1,61)}=361.27, p<1 \times 10^{-15} ; F_{\text {genotype }(1,61)}=1.44, p=0.23 ; F_{\text {treatment }(1,61)}$ $=0.08, p=0.78 ; F_{\text {surgery } \times \text { genotype }(1,61)}=9.63, p=0.99 ; F_{\text {surgery } \times \text { treatment }(1,61)}=0.74, p=0.39 ; F_{\text {genotype } \times \text { treatment }(1,61)}=1.10, p=0.30$ for the values of ipsilateral side at $\left.0.4 \mathrm{~g}\right)$. Data are expressed as the mean \pm SEM and scatter plots.

the CCI-operated side, and in $37.8 \%$ of GFAP-positive cells on the sham-operated side. These data indicate that TRPM3 is expressed in a large fraction of neurons and in a smaller portion of glial cells in the spinal dorsal horn. Our data are consistent with recent single-cell RNA sequencing studies showing clear expression of TRPM3 in dorsal horn neurons (Häring et al., 2018; Sathyamurthy et al., 2018), as well as in spinal cord astrocytes (Sathyamurthy et al., 2018). In DRGs, the TRPM3 probe showed clear colocalization with the neuronal marker NeuN (data not shown). We also detected some colocalization of 
A

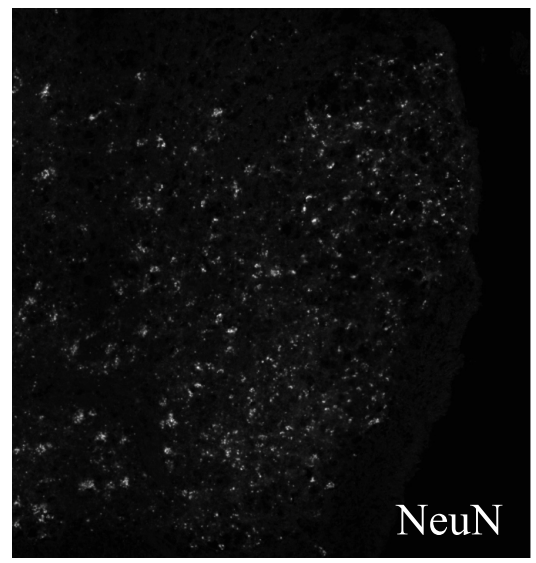

B

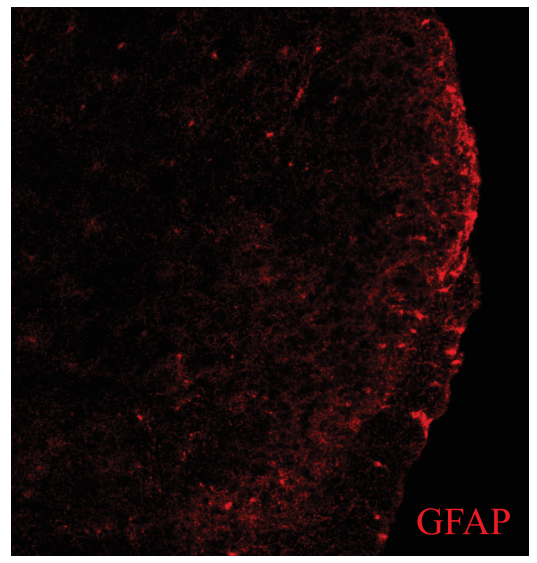

C

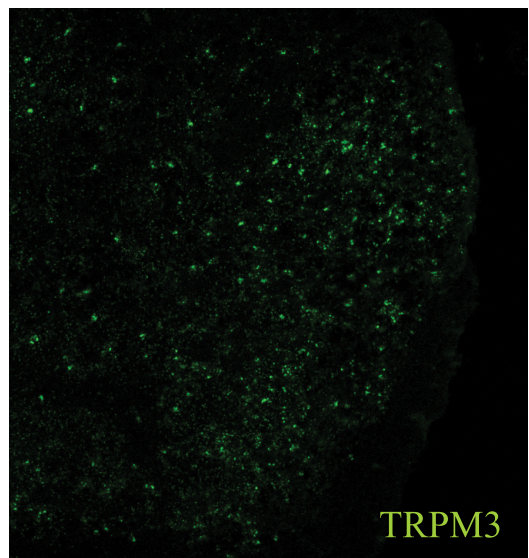

D

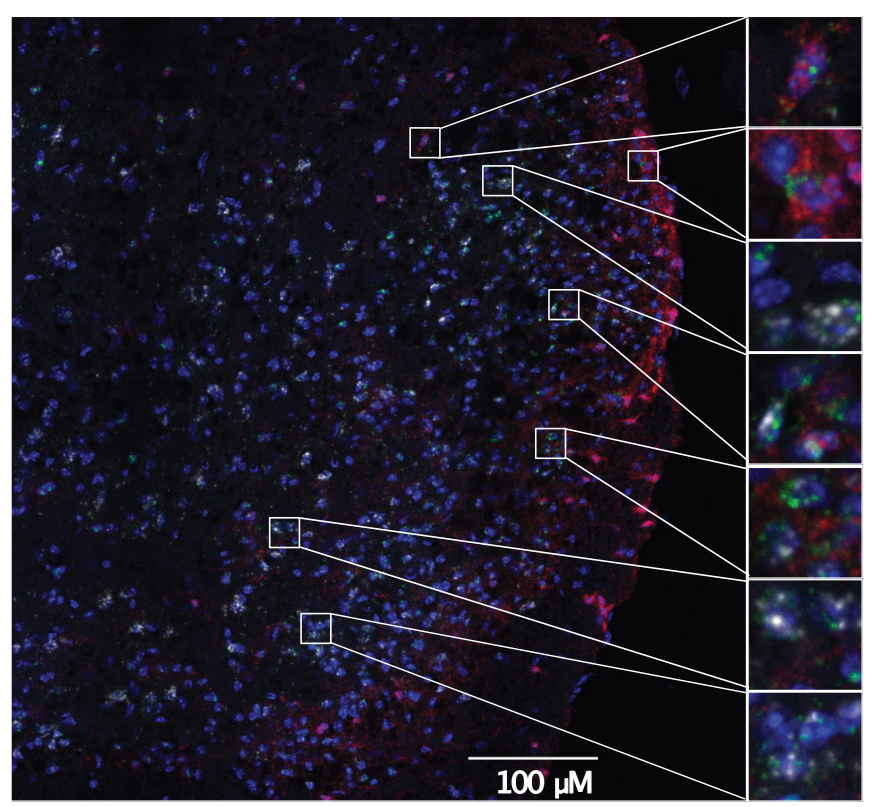

E

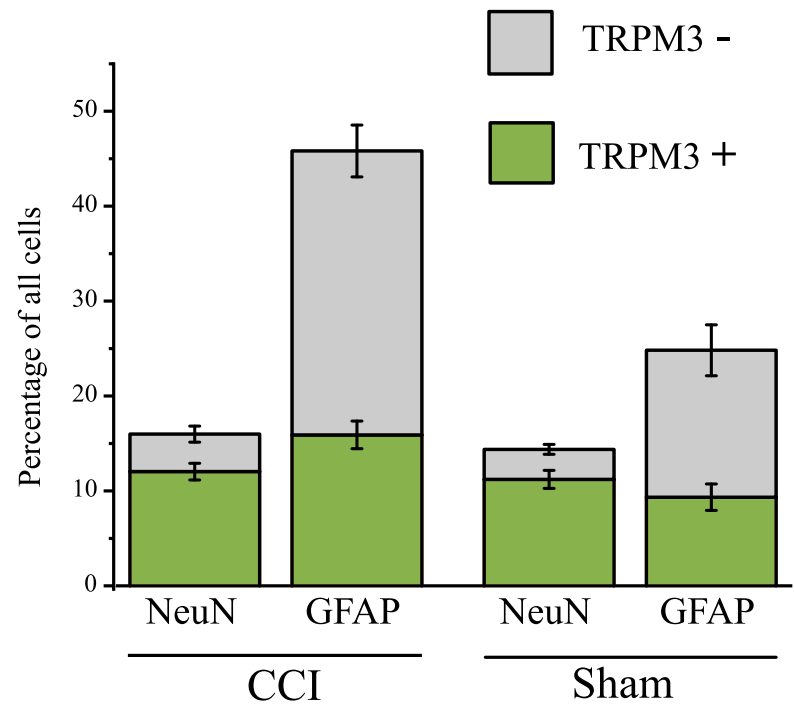

Figure 10. TRPM3 is expressed both in the DRG and in the dorsal horn. Multiplex fluorescence in situ hybridization experiments using the RNAScope system were performed as described in the Materials and Methods section. $\boldsymbol{A}-\boldsymbol{C}$, Confocal images taken with a $40 \times$ objective of a representative dorsal horn section from the side of $C(C)$ operation at different individual fluorescence channels for the neuronal marker NeuN ( $\boldsymbol{A}$, white), the glial marker GFAP ( $\boldsymbol{B}$, red) and for TRPM3 ( $\boldsymbol{C}$, green). $\boldsymbol{D}$, Merged image for the three channels plus the nuclear stain DAPI, insets on the right side show enlarged parts of the slide. $\boldsymbol{E}$, Quantification of the proportion of TRPM3-positive cells among NeuN-positive cells (neurons) and GFAP-positive cells (glia), $n=6$ different spinal cord preparations. The colocalization was assessed by the CellProfiler software. Data are shown as the mean \pm SEM, for $n=6$ different dorsal horn preparations, two to three sections each, the data from different sections from the same preparation were averaged and taken as one data point.

TRPM3 with the glial marker GFAP, but because of the small size of glial satellite cells and their close attachment to the cell bodies of DRG neurons, these data were difficult to quantify (data not shown). These data are consistent with the well known functional expression of TRPM3 in DRG neurons, and with our earlier $\mathrm{Ca}^{2+}$ imaging experiments showing that in isolated cells from dorsal root ganglia, a fraction of non-neuronal cells also responded to the TRPM3 agonist PregS (Badheka et al., 2017).

To test whether TRPM3 channels in the central termini of the DRGs or in the dorsal horn are involved in mediating the effect of systemic primidone, we injected $0.5 \mu \mathrm{g}$ of primidone intrathecally. Figure $11 \mathrm{~A}$ shows that intrathecal primidone increased the latency of withdrawal from radiant heat in both CCI- and shamoperated wild-type animals, but not in TRPM3 $3^{-1-}$ mice on the side of CCI operation. On the contralateral side, CCI- operated animals showed similar thermal responses to sham-operated mice, and primidone increased withdrawal latency in both groups in wild-type, but not in TRPM3 ${ }^{-1-}$ mice (Fig. 11B). Similar to local hindpaw injection, intrathecal primidone had no effect on mechanical responses in the von Frey assay (Fig. 11C-F).

Finally, we tested the effect of intrathecal injection of the TRPM3 agonist CIM0216 on heat sensitivity and c-Fos and pERK level. Figure 12, $A$ and $B$, shows that intrathecal injection of CIM0216 $(25 \mathrm{nmol})$ reduced the latency of paw withdrawal from radiant heat both in the left and the right hindpaw in wildtype mice, but not in TRPM3 ${ }^{-1-}$ mice. Figure $12 C-E$ shows that intrathecal injection of CIM0216 increased the number of c-Fosand pERK-positive cells in the dorsal horn. The increase in c-Fos and pERK was significantly smaller in TRPM3 ${ }^{-1-}$ mice, but it did not completely disappear, indicating that CIM0216 increased 
A

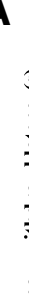

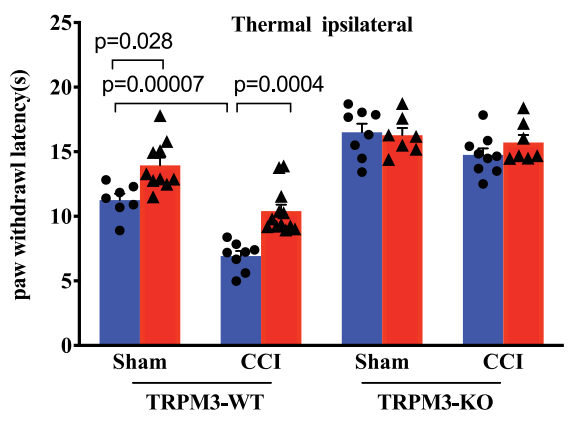

C

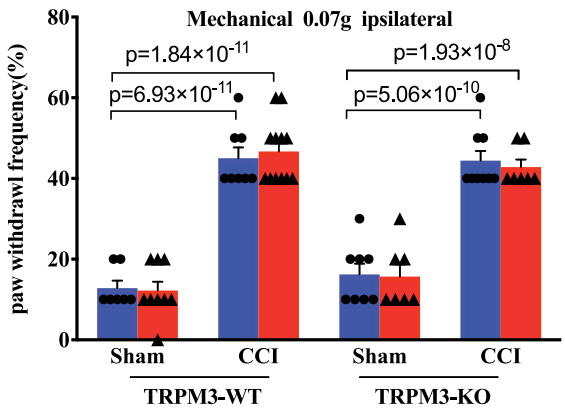

E

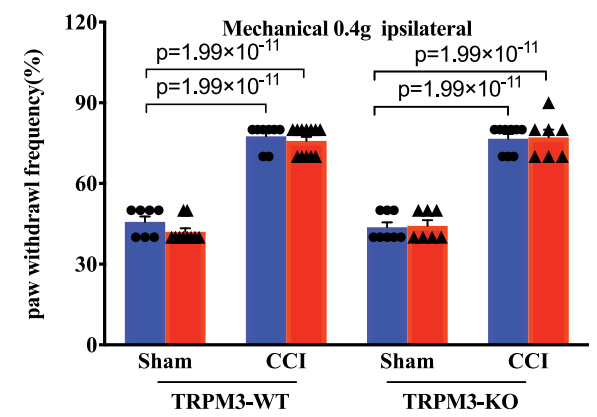

B


$\mathbf{F}$

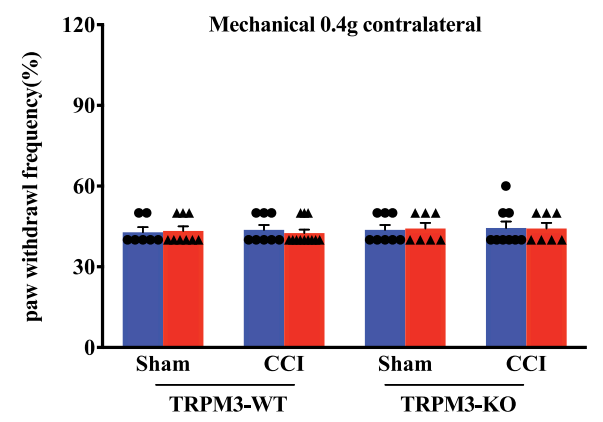

Figure 11. The effect of intrathecal primidone administration on nociceptive behaviors following CCl surgery in WT and TRPM3-KO mice. $\boldsymbol{A}, \boldsymbol{B}$, The effect of intrathecal injection of primidone on paw withdrawal latency to thermal stimuli in the Hargreaves test on the ipsilateral $(\boldsymbol{A})$ and contralateral $(\boldsymbol{B})$ side in TRPM3-WT and TRPM3-KO mice on day 6 after $C(\mathrm{Cl}$ or sham surgery $(n=$ 7-12). Statistical significance was calculated with three-way ANOVA (surgery $\times$ genotype $\times$ treatment) with Tukey's post hoc test, $F_{\text {surgery }(1,60)}=40.73, p=2.80 \times 10^{-8} ; F_{\text {genotype }(1,60)}=$ $167.69, p<1 \times 10^{-15} ; F_{\text {treatment }(1,60)}=18.60, p=6.08 \times 10^{-5} ; F_{\text {surgery }} \times$ genotype $(1,60)=12.24, p=0.0009 ; F_{\text {surgery }} \times$ treatment $(1,60)=1.55, p=0.22 ; F_{\text {genotype }} \times$ treatment $(1,60)=11.51$, $p=0.001$ for the values at the ipsilateral side; $F_{\text {surgery }(1,60)}=1.11, p=0.30 ; F_{\text {genotype }(1,60)}=91.89, p=1.03 \times 10^{-13} ; F_{\text {treatment }(1,60)}=11.57, p=0.001 ; F_{\text {surgery }} \times$ genotype $(1,60)=0.07, p=0.79$; $F_{\text {surgery } \times \text { treatment }(1,60)}=0.0001, p=0.99 ; F_{\text {genotype } \times \text { treatment }(1,60)}=9.39, p=0.003$ for the values at the contralateral side. $\boldsymbol{C}-\boldsymbol{F}$, The effect of intrathecal primidone on paw withdrawal frequency to mechanical stimulation in the von Frey test at $0.07 \mathrm{~g}(\boldsymbol{C}$, ipsilateral; $\boldsymbol{D}$, contralateral) and $0.4 \mathrm{~g}(\boldsymbol{E}$, ipsilateral; $\boldsymbol{F}$, contralateral) of TRPM3-WT and TRPM3-K0 mice on day 6 after $(\boldsymbol{C l}$ or sham surgery $(n=7-12)$. Statistical significance was calculated with three-way ANOVA (surgery $\times$ genotype $\times$ treatment) with Tukey's post hoc test $\left(F_{\text {surgery }(1,59)}=308.47, p<1 \times\right.$ $10^{-15} ; F_{\text {genotype }(1,59)}=0.13, p=0.72 ; F_{\text {treatment }(1,59)}=0.02, p=0.88 ; F_{\text {surgery } \times \text { genotype }(1,59)}=2.63, p=0.11 ; F_{\text {surgeny }} \times$ treatment $(1,59)=0.03, p=0.86 ; F_{\text {genotype } \times \text { treatment }(1,59)}=0.21, p=0.65$ for the values of ipsilateral side at $0.07 \mathrm{~g} ; F_{\text {surgery }(1,60)}=635.61, p<1 \times 10^{-15} ; F_{\text {genotype }(1,60)}=0.02, p=0.88 ; F_{\text {treatment }(1,60)}=0.70, p=0.41 ; F_{\text {surgery }} \times$ genotype $(1,60)=0.0009, p=0.98$; $F_{\text {surgery } \times \text { treatment }(1,60)}=0.15, p=0.70 ; F_{\text {genotype } \times \text { treatment }(1,60)}=1.50, p=0.22$ for the values of ipsilateral side at $\left.0.4 \mathrm{~g}\right)$. Data are expressed as the mean \pm SEM and scatter plots.

neural activity both in a TRPM3-dependent and TRPM3-independent manner. Overall, these data further support the role of TRPM3 located in the central termini of DRG neurons or in the dorsal horn in modulating heat sensitivity.

\section{Discussion}

TRPM3 is a heat-activated ion channel expressed in DRG neurons. While the role of this channel is well established in noxious heat sensation (Vriens et al., 2011; Vandewauw et al., 2018), its role in cold and mechanosensation has been controversial. Here we used a combination of genetic and pharmacological tools and show that TRPM3 plays a role in noxious heat sensation, but not in cold and mechanical hyperalgesia after peripheral nerve injury. Our data also uncover a role of TRPM3 in spontaneous pain in nerve injury-induced neuropathy, as well as a role of
TRPM3 located in the spinal cord, or in the central processes, or in cell bodies of DRG neurons in modulating heat sensitivity.

The low temperature threshold of TRPM3 (Vriens et al., 2011; Zhao et al., 2020) makes this channel an ideal candidate for mediating spontaneous pain, but this possibility has not been addressed previously. Here we show that systemic injection of the TRPM3 inhibitor isosakuranetin increased the preference for the drug-paired chamber in the CPP assay, and this effect was reduced, or eliminated in TRPM3 ${ }^{-1-}$ mice depending on the dose of isosakuranetin. We also show that the levels of c-Fos and pERK, early markers of neuronal activity, increased in the spinal cord and DRGs of CCI-operated animals compared with sham-operated mice, and this increase was smaller in TRPM3 $3^{-1-}$ mice and was reduced by systemic injection of TRPM3 inhibitors. Overall, these data indicate that TRPM3 plays a role in spontaneous neural activity and pain in peripheral nerve injury-induced neuropathy. 
A




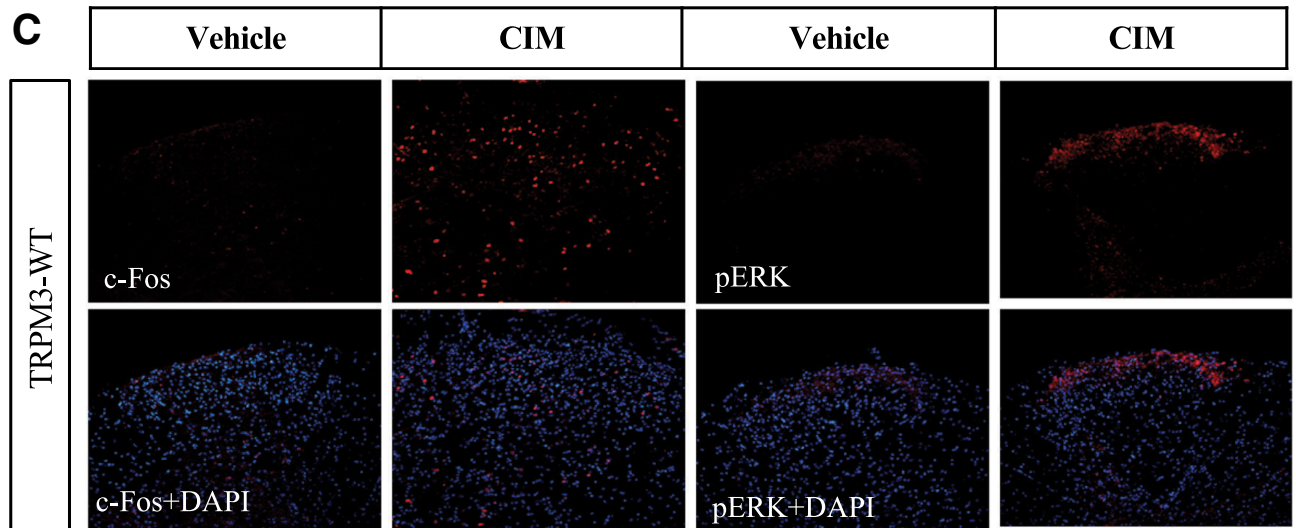

c-Fos+DAPI
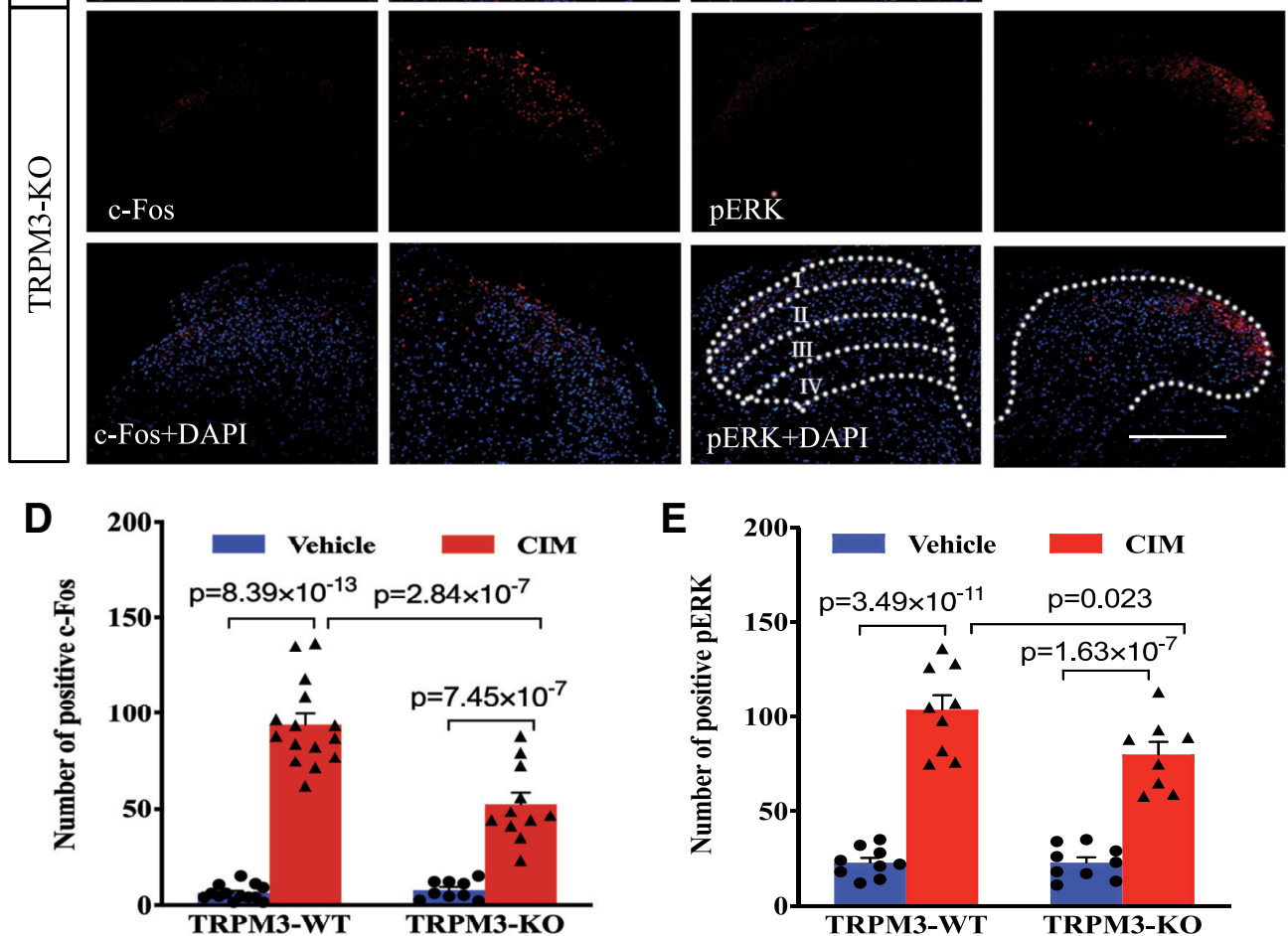

Figure 12. The effect of intrathecal administration of the TRPM3 agonist CIM0216 on nociceptive behavioral responses and pronociceptive signal transduction protein expressions in dorsal spinal cord. $\boldsymbol{A}, \boldsymbol{B}$, The effect of CIM0126 on paw withdrawal latency to thermal stimuli in the Hargreaves test of left and right sides ( $n=10-19)$. Statistical significance was calculated with two-way ANOVA (genotype $\times$ treatment) with Tukey's post hoc test $\left(F_{\text {genotype }(1,85)}=95.80, p=1 \times 10^{-15} ; F_{\text {treatment }(2,85)}=5.62, p=0.005 ; F_{\text {genotype }} \times\right.$ treatment $(2,85)=1.75, p=0.18$ for the values of left side; $F_{\text {genotype }(1,83)}=83.02, p=3.90 \times 10^{-14} ; F_{\text {treatment(2,83) }}=6.09, p=0.003 ; F_{\text {genotype } \times \text { treatment }(2,83)}=0.21, p=0.81 \mathrm{for}$ the values of right side). $C$, Sections of $c$-Fos (left) and pERK (right) in L3-L5 dorsal spinal cord of TRPM3-WT and TRPM3-KO mice at 30 min after CIM0216 or vehicle injection. Scale bars, $50 \mu \mathrm{m}$. $\boldsymbol{D}, \boldsymbol{E}$, The numbers of c-Fos-positive cells (D) and pERKpositive cells $(E)$ in the sections were counted ( $n=8-15$ sections from three independent preparations). Statistical significance was calculated with two-way ANOVA (genotype $\times$ treatment) followed by Tukey's multiple comparisons test $\left(F_{\text {genotype }(1,44)}=18.27, p=0.0001 ; F_{\text {treatment }(1,44)}=202.31, p<1 \times 10^{-15} ; F_{\text {genotype } \times \text { treatment }(1,44)}=21.21, p=4.0 \times 10^{-5}\right.$ for $c-$ Fos expression; $F_{\text {genotype }(1,31)}=4.79$, $p=0.036, F_{\text {treatment }(1,31)}=162.50, p=7.30 \times 10^{-14} ; F_{\text {genotype }} \times$ treatment $(1,31)=4.79, p=0.036$ for $p$ ERK expression). Data are expressed as the mean \pm SEM and scatter plots.

Thermal and mechanical stimuli are sensed by peripheral processes of the DRG neurons. Consistent with this, we found that not only systemic injection, but also intraplantar injection of primidone inhibited thermal hyperalgesia after CCI. TRP channels, however, are also known to be present in the central processes of DRG neurons (Kim et al., 2014), and TRPM3 RNA has been detected in the spinal cord with RT-PCR (Lee et al., 2003), and single-cell RNA sequencing studies showed 
expression of TRPM3 in dorsal horn neurons (Häring et al., 2018; Sathyamurthy et al., 2018), as well as in spinal cord astrocytes (Sathyamurthy et al., 2018). Our in situ hybridization data confirmed these earlier observations. To address the role of TRPM3 located in the spinal cord, or in the central termini of DRG neurons, we injected primidone intrathecally. We find that intrathecal injection of primidone reduced heat sensitivity both in naive and CCI-operated wild-type animals, but not in $\mathrm{TRPM}^{-1-}$ mice. Furthermore, intrathecal injection of the TRPM3 agonist CIM0216 decreased the latency of withdrawal of the hindpaw from radiant heat in wild-type mice but not in $\mathrm{TRPM}^{-1-}$ mice. Intrathecal injection of fluorescein was shown to label not only the spinal cord, but also proximal portions of the DRGs (Abram et al., 2006). Thus, the cell bodies of the DRG neurons, or the T-junction of the nociceptive fibers, which were shown recently to play important roles in nociceptive signal processing (Du et al., 2017), are also potential sites of action for the TRPM3 antagonist. These data indicate that TRPM3 located in the dorsal horn, or in the central termini, or cell bodies of DRGs modulate heat sensitivity. Determining the exact site of action of the TRPM3 agonist after intrathecal injection will require future studies using tissue-specific TRPM3 knock-out mice.

TRPM3 is expressed in the brain, and its overactive mutations cause intellectual disability and epilepsy in humans (Dyment et al., 2019; Van Hoeymissen et al., 2020; Zhao et al., 2020). Primidone crosses the blood-brain barrier (Nagaki et al., 1999), while specific data for isosakuranetin are not available, several very similar flavonoid molecules, such as liquiritigenin and naringenin (also TRPM3 inhibitors) have been shown to cross the blood-brain barrier (Youdim et al., 2003; Li et al., 2015a). We found that local primidone injection either in the paw, or intrathecally exerted a similar effect to that of systemic injection, which argues against a substantial role of TRPM3 in the brain in the analgesic effects of TRPM3 antagonists.

It was shown that systemic injection of the isosakuranetin $(1.5-6 \mathrm{mg} / \mathrm{kg})$ reduced not only heat hypersensitivity, but also mechanical and cold hyperalgesia in the CCI model of neuropathic pain in rats (Jia et al., 2017). Liquiritigenin, another flavanone inhibitor of TRPM3, also reduced heat, mechanical, and cold hypersensitivity in rats in the CCI model (Chen et al., 2014). Here we reproduce these data with isosakuranetin in the mouse CCI model and show that the effect of isosakuranetin on heat sensitivity disappears in TRPM3 $3^{-1-}$ mice, which is consistent with the well established role of this channel as a noxious heat sensor (Vriens and Voets, 2018). We also find that $2 \mathrm{mg} / \mathrm{kg}$ isosakuranetin reduced cold and mechanical hypersensitivity in CCI mice, but this effect persisted in the TRPM3 ${ }^{-1-}$ mice, indicating that this flavanone compound alleviated cold and mechanical hypersensitivity independent of its effect on TRPM3. Consistent with this, a lower dose $(0.5 \mathrm{mg} / \mathrm{kg})$ still showed inhibition of heat sensitivity, but it did not reduce mechanical and cold sensitivity.

In the CPP assay, CCI mice showed preference for the isosakuranetin-paired chamber, and in $\mathrm{TRPM}^{-1-}$ mice this effect was reduced at $2 \mathrm{mg} / \mathrm{kg}$ and not observed at $0.5 \mathrm{mg} / \mathrm{kg}$ isosakuranetin. This indicates that isosakuranetin alleviates spontaneous pain via a combination of TRPM3-dependent and TRPM3-independent pathways, depending on its dose.

Systemic injection of primidone had no effect on cold sensitivity in CCI mice, indicating that TRPM3 does not play a role in cold sensation. Systemic injection of primidone showed a somewhat mixed effect on mechanical sensitivity. It showed a small but statistically significant reduction in withdrawal frequency in the von Frey assay to $0.4 \mathrm{~g}$ filaments in wild-type mice, but not in TRPM3 ${ }^{-1-}$ mice. In response to $0.07 \mathrm{~g}$, however, it showed a small, statistically nonsignificant decrease in both wild-type and $\mathrm{TRPM}^{-1-}$ mice. Unlike heat responses, mechanical responses were not different between wild-type and TRPM3 ${ }^{-1-}$ mice at baseline or after CCI surgery. Furthermore, unlike for heat responses, neither intraplantar nor intrathecal injection of primidone had a significant effect on mechanical sensitivity. In aggregate, these data show that TRPM3 does not play a major role in mechanical hypersensitivity after nerve injury.

Both TRPM3 inhibitors consistently reduced heat sensitivity in CCI mice, but paw withdrawal latencies were still lower than in TRPM3 $3^{-1-}$ mice for both drugs, regardless of the dose, or the route of application. In sham-operated animals, on the other hand, both drugs brought the paw withdrawal latencies to levels similar to that observed in TRPM3 ${ }^{-1-}$ mice. The reason for this discrepancy is unclear. One possibility is that in response to nerve injury TRPM3 channels undergo post-translational modification or a change in splicing that renders them less sensitive to inhibitors. Another possibility is that acute inhibition of the channel has a different effect than chronic absence caused by genetic deletion. Differentiating between these possibilities will require future experiments.

Overall, our data indicate that TRPM3 plays a role in spontaneous pain and thermal hyperalgesia in neuropathic pain. Our data also uncover a role of TRPM3 located in the spinal cord, the central processes, or cell bodies of DRG neurons in modulating heat sensitivity.

\section{References}

Abram SE, Yi J, Fuchs A, Hogan QH (2006) Permeability of injured and intact peripheral nerves and dorsal root ganglia. Anesthesiology 105:146153.

Adriaenssens AE, Biggs EK, Darwish T, Tadross J, Sukthankar T, Girish M, Polex-Wolf J, Lam BY, Zvetkova I, Pan W, Chiarugi D, Yeo GSH, Blouet C, Gribble FM, Reimann F (2019) Glucose-dependent insulinotropic polypeptide receptor-expressing cells in the hypothalamus regulate food intake. Cell Metab 30:987-996.e6.

Badheka D, Yudin Y, Borbiro I, Hartle CM, Yazici A, Mirshahi T, Rohacs T (2017) Inhibition of transient receptor potential melastatin 3 ion channels by G-protein $\beta \gamma$ subunits. Elife 6:e26147.

Behrendt M (2019) Transient receptor potential channels in the context of nociception and pain-recent insights into TRPM3 properties and function. Biol Chem 400:917-926.

Bennett GJ, Xie YK (1988) A peripheral mononeuropathy in rat that produces disorders of pain sensation like those seen in man. Pain 33:87-107.

Berta T, Park CK, Xu ZZ, Xie RG, Liu T, Lü N, Liu YC, Ji RR (2014) Extracellular caspase- 6 drives murine inflammatory pain via microglial TNF- $\alpha$ secretion. J Clin Invest 124:1173-1186.

Cao J, Wang JS, Ren XH, Zang WD (2015a) Spinal sample showing p-JNK and P38 associated with the pain signaling transduction of glial cell in neuropathic pain. Spinal Cord 53:92-97.

Cao J, Wang PK, Tiwari V, Liang L, Lutz BM, Shieh KR, Zang WD, Kaufman AG, Bekker A, Gao XQ, Tao YX (2015b) Short-term pre- and post-operative stress prolongs incision-induced pain hypersensitivity without changing basal pain perception. Mol Pain 11:73.

Carnevale V, Rohacs T (2016) TRPV1: a target for rational drug design. Pharmaceuticals 9:52.

Chen L, Chen W, Qian X, Fang Y, Zhu N (2014) Liquiritigenin alleviates mechanical and cold hyperalgesia in a rat neuropathic pain model. Sci Rep 4:5676.

Dembla S, Behrendt M, Mohr F, Goecke C, Sondermann J, Schneider FM, Schmidt M, Stab J, Enzeroth R, Leitner MG, Nuñez-Badinez P, Schwenk J, Nürnberg B, Cohen A, Philipp SE, Greffrath W, Bünemann M, Oliver D, Zakharian E, Schmidt M, et al. (2017) Anti-nociceptive action of peripheral mu-opioid receptors by G-beta-gamma protein-mediated inhibition of TRPM3 channels. Elife 6:e26280. 
Du X, Hao H, Yang Y, Huang S, Wang C, Gigout S, Ramli R, Li X, Jaworska E, Edwards I, Deuchars J, Yanagawa Y, Qi J, Guan B, Jaffe DB, Zhang H, Gamper N (2017) Local GABAergic signaling within sensory ganglia controls peripheral nociceptive transmission. J Clin Invest 127:1741-1756.

Dyment DA, Terhal PA, Rustad CF, Tveten K, Griffith C, Jayakar P, Shinawi M, Ellingwood S, Smith R, van Gassen K, McWalter K, Innes AM, Lines MA (2019) De novo substitutions of TRPM3 cause intellectual disability and epilepsy. Eur J Hum Genet 27:1611-1618.

Erben L, He MX, Laeremans A, Park E, Buonanno A (2018) A novel ultrasensitive in situ hybridization approach to detect short sequences and splice variants with cellular resolution. Mol Neurobiol 55:6169-6181.

Gao YJ, Zhang L, Ji RR (2010) Spinal injection of TNF- $\alpha$-activated astrocytes produces persistent pain symptom mechanical allodynia by releasing monocyte chemoattractant protein-1. Glia 58:1871-1880.

Glazko AJ (1975) Antiepileptic drugs: biotransformation, metabolism, and serum half-life. Epilepsia 16:367-391.

Guo JR, Wang H, Jin XJ, Jia DL, Zhou X, Tao Q (2017) Effect and mechanism of inhibition of PI3K/Akt/mTOR signal pathway on chronic neuropathic pain and spinal microglia in a rat model of chronic constriction injury. Oncotarget 8:52923-52934.

Häring M, Zeisel A, Hochgerner H, Rinwa P, Jakobsson JET, Lönnerberg P, La Manno G, Sharma N, Borgius L, Kiehn O, Lagerström MC, Linnarsson S, Ernfors P (2018) Neuronal atlas of the dorsal horn defines its architecture and links sensory input to transcriptional cell types. Nat Neurosci 21:869-880.

Held K, Kichko T, De Clercq K, Klaassen H, Van Bree R, Vanherck JC, Marchand A, Reeh PW, Chaltin P, Voets T, Vriens J (2015) Activation of TRPM3 by a potent synthetic ligand reveals a role in peptide release. Proc Natl Acad Sci U S A 112:E1363-E1372.

Jia S, Zhang Y, Yu J (2017) Antinociceptive effects of isosakuranetin in a rat model of peripheral neuropathy. Pharmacology 100:201-207.

Kim YS, Chu Y, Han L, Li M, Li Z, LaVinka PC, Sun S, Tang Z, Park K, Caterina MJ, Ren K, Dubner R, Wei F, Dong X (2014) Central terminal sensitization of TRPV1 by descending serotonergic facilitation modulates chronic pain. Neuron 81:873-887.

Koh WU, Choi SS, Lee JH, Lee SH, Lee SK, Lee YK, Leem JG, Song JG, Shin JW (2014) Perineural pretreatment of bee venom attenuated the development of allodynia in the spinal nerve ligation injured neuropathic pain model; an experimental study. BMC Complement Altern Med 14:431.

Krügel U, Straub I, Beckmann H, Schaefer M (2017) Primidone inhibits TRPM3 and attenuates thermal nociception in vivo. Pain 158:856-867.

Lee N, Chen J, Sun L, Wu S, Gray KR, Rich A, Huang M, Lin JH, Feder JN, Janovitz EB, Levesque PC, Blanar MA (2003) Expression and characterization of human transient receptor potential melastatin 3 (hTRPM3). J Biol Chem 278:20890-20897.

Lee SH, Cho PS, Tonello R, Lee HK, Jang JH, Park GY, Hwang SW, Park CK, Jung SJ, Berta T (2018) Peripheral serotonin receptor 2B and transient receptor potential channel 4 mediate pruritus to serotonergic antidepressants in mice. J Allergy Clin Immunol 142:1349-1352.e16.

Li H, Ye M, Zhang Y, Huang M, Xu W, Chu K, Chen L, Que J (2015a) Blood-brain barrier permeability of Gualou Guizhi granules and neuroprotective effects in ischemia/reperfusion injury. Mol Med Rep 12:12721278.

Li Z, Gu X, Sun L, Wu S, Liang L, Cao J, Lutz BM, Bekker A, Zhang W, Tao YX (2015b) Dorsal root ganglion myeloid zinc finger protein 1 contributes to neuropathic pain after peripheral nerve trauma. Pain 156:711721.

Li Y, Guo X, Sun L, Xiao J, Su S, Du S, Li Z, Wu S, Liu W, Mo K, Xia S, Chang YJ, Denis D, Tao YX (2020) N(6)-methyladenosine demethylase FTO contributes to neuropathic pain by stabilizing G9a expression in primary sensory neurons. Adv Sci (Weinh) 7:1902402.

Li Z, Mao Y, Liang L, Wu S, Yuan J, Mo K, Cai W, Mao Q, Cao J, Bekker A, Zhang W, Tao YX (2017) The transcription factor C/EBPbeta in the dorsal root ganglion contributes to peripheral nerve trauma-induced nociceptive hypersensitivity. Sci Signal 10:eaam5345.

Liu DL, Lu N, Han WJ, Chen RG, Cong R, Xie RG, Zhang YF, Kong WW, Hu SJ, Luo C (2015) Upregulation of Ih expressed in IB4-negative A $\delta$ nociceptive DRG neurons contributes to mechanical hypersensitivity associated with cervical radiculopathic pain. Sci Rep 5:16713.

Mo K, Wu S, Gu X, Xiong M, Cai W, Atianjoh FE, Jobe EE, Zhao X, Tu WF, Tao YX (2018) MBD1 contributes to the genesis of acute pain and neuropathic pain by epigenetic silencing of Oprm1 and Kcna2 genes in primary sensory neurons. J Neurosci 38:9883-9899.

Nadal X, Baños JE, Kieffer BL, Maldonado R (2006) Neuropathic pain is enhanced in delta-opioid receptor knockout mice. Eur J Neurosci 23:830-834

Nagaki S, Ratnaraj N, Patsalos PN (1999) Blood and cerebrospinal fluid pharmacokinetics of primidone and its primary pharmacologically active metabolites, phenobarbital and phenylethylmalonamide in the rat. Eur J Drug Metab Pharmacokinet 24:255-264.

Oberwinkler J, Philipp SE (2014) Trpm3. Handb Exp Pharmacol 222:427459

Quallo T, Alkhatib O, Gentry C, Andersson DA, Bevan S (2017) G protein betagamma subunits inhibit TRPM3 ion channels in sensory neurons. Elife 6:e26138.

Sathyamurthy A, Johnson KR, Matson KJE, Dobrott CI, Li L, Ryba AR, Bergman TB, Kelly MC, Kelley MW, Levine AJ (2018) Massively parallel single nucleus transcriptional profiling defines spinal cord neurons and their activity during behavior. Cell Rep 22:2216-2225.

Straub I, Krügel U, Mohr F, Teichert J, Rizun O, Konrad M, Oberwinkler J, Schaefer M (2013) Flavanones that selectively inhibit TRPM3 attenuate thermal nociception in vivo. Mol Pharmacol 84:736-750.

Sun L, Gu X, Pan Z, Guo X, Liu J, Atianjoh FE, Wu S, Mo K, Xu B, Liang L, Bekker A, Tao YX (2019) Contribution of DNMT1 to neuropathic pain genesis partially through epigenetically repressing Kcna2 in primary afferent neurons. J Neurosci 39:6595-6607.

Tanimoto-Mori S, Nakazato-Imasato E, Toide K, Kita Y (2008) Pharmacologic investigation of the mechanism underlying cold allodynia using a new cold plate procedure in rats with chronic constriction injuries. Behav Pharmacol 19:85-90.

Tappe-Theodor A, Kuner R (2014) Studying ongoing and spontaneous pain in rodents-challenges and opportunities. Eur J Neurosci 39:1881-1890.

Van Hoeymissen E, Held K, Nogueira Freitas AC, Janssens A, Voets T, Vriens J (2020) Gain of channel function and modified gating properties in TRPM3 mutants causing intellectual disability and epilepsy. Elife 9: e57190.

Vandewauw I, De Clercq K, Mulier M, Held K, Pinto S, Van Ranst N, Segal A, Voet T, Vennekens R, Zimmermann K, Vriens J, Voets T (2018) A TRP channel trio mediates acute noxious heat sensing. Nature 555:662666.

Vriens J, Voets T (2018) Sensing the heat with TRPM3. Pflugers Arch 470:799-807.

Vriens J, Owsianik G, Hofmann T, Philipp SE, Stab J, Chen X, Benoit M, Xue F, Janssens A, Kerselaers S, Oberwinkler J, Vennekens R, Gudermann T, Nilius B, Voets T (2011) TRPM3 is a nociceptor channel involved in the detection of noxious heat. Neuron 70:482-494.

Vriens J, Nilius B, Voets T (2014) Peripheral thermosensation in mammals. Nat Rev Neurosci 15:573-589.

Wagner TF, Loch S, Lambert S, Straub I, Mannebach S, Mathar I, Düfer M, Lis A, Flockerzi V, Philipp SE, Oberwinkler J (2008) Transient receptor potential M3 channels are ionotropic steroid receptors in pancreatic beta cells. Nat Cell Biol 10:1421-1430.

Warren BL, Kane L, Venniro M, Selvam P, Quintana-Feliciano R, Mendoza MP, Madangopal R, Komer L, Whitaker LR, Rubio FJ, Bossert JM, Caprioli D, Shaham Y, Hope BT (2019) Separate vmPFC ensembles control cocaine self-administration versus extinction in rats. J Neurosci 39:7394-7407.

Woodhams SG, Markus R, Gowler PRW, Self TJ, Chapman V (2019) Cell type-specific super-resolution imaging reveals an increase in calcium-permeable AMPA receptors at spinal peptidergic terminals as an anatomical correlate of inflammatory pain. Pain 160:2641-2650.

Youdim KA, Dobbie MS, Kuhnle G, Proteggente AR, Abbott NJ, Rice-Evans C (2003) Interaction between flavonoids and the blood-brain barrier: in vitro studies. J Neurochem 85:180-192.

Yudin Y, Rohacs T (2019) The G protein-biased agents PZM21 and TRV130 are partial agonists of $\mu$-opioid receptor-mediated signalling to ion channels. Br J Pharmacol 176:3110-3125.

Zhao S, Yudin Y, Rohacs T (2020) Disease-associated mutations in the human TRPM3 render the channel overactive via two distinct mechanisms. Elife 9:e55634. 